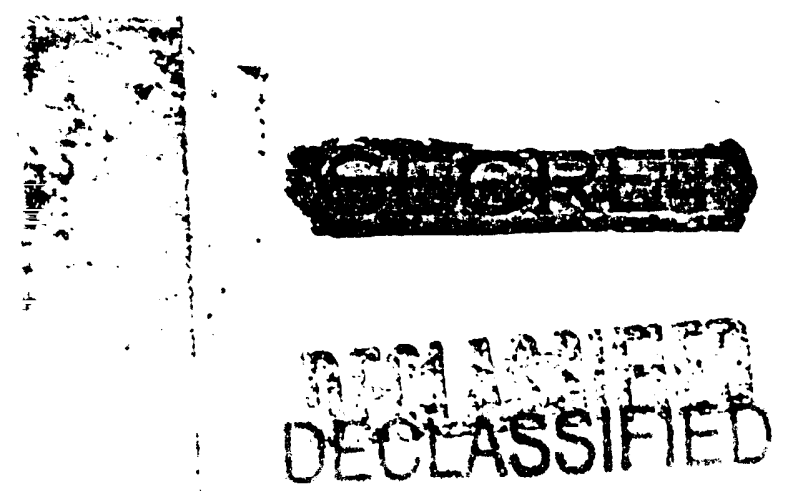

\begin{tabular}{|c|c|c|}
\hline \multirow{2}{*}{$\begin{array}{l}\text { CIRCUIATING COPY } \\
\text { RECEIVED } 300 \text { AREA }\end{array}$} & & $\mathrm{HW}--52340$ \\
\hline & & DE93 010219 \\
\hline SEP $25 \quad 957$ & FAD & \\
\hline FETLiniv TO & & \\
\hline twi & & \\
\hline
\end{tabular}

\title{
PROCESS TUBE BOILOUT EXPERIMENTS
}

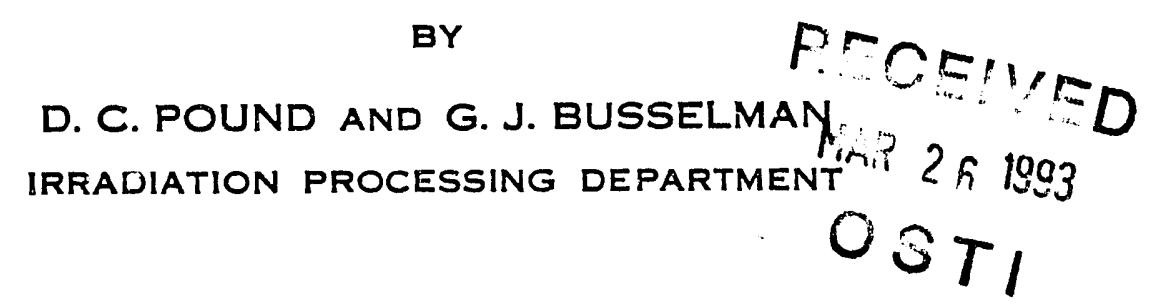

AUGUST 23, 1957

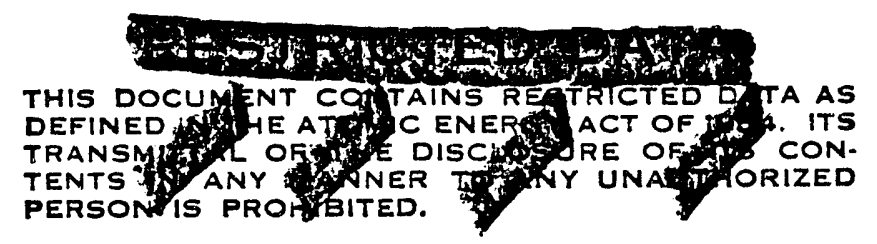

HANFORD ATOMIC PRODUCTS OPERATION

RICHLAND, WASHINGTON

\section{GENERAL ELETRIC}

DEQLASSIFIED

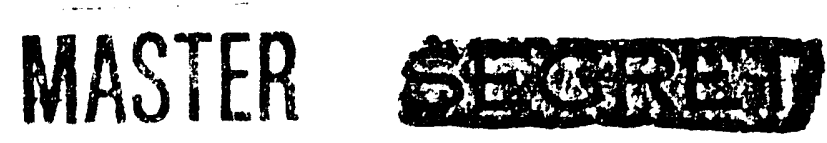




\section{DECLASSIFIED}

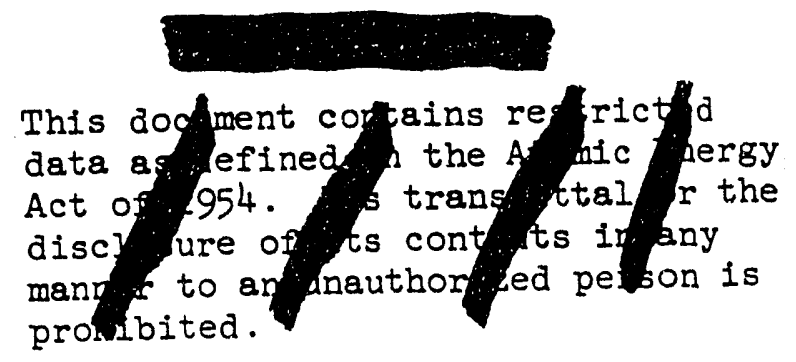

This document consists of

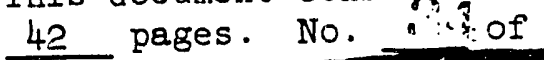

49 copies.

This document classified by:
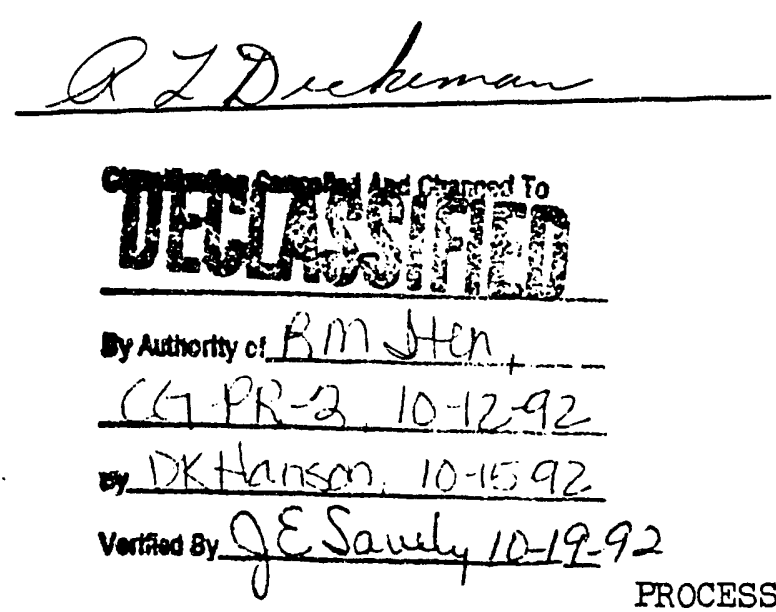

PROCESS TUBE BOILOUT EXPERIMENTS
1-20. AEC-HOO, Atten: J. E. Travis

2l-22. AEC-HOO, Atten: A. T. Gifford

23-24. AEC-HOO, Atten: H. H. Schipper

25. FW Albaugh

26. WK Alexander

27. RS Bell

28. IP Bupp - IH McEwen

29. $A B$ Carson - HW Heacock

30. RL Dickeman - JH Brown

31. GC Fullmer - RO Brugge

32. OH Greager

33. $A B$ Greninger

34. PF Gast

35. CN Gross

36. WM Harty

37. RT Jessen

38. AR Maguire

39. WW McIntosh

40. JS McMahon

41. CL Miller - Gư Busselman

42. JF Music - HG Spencer

43. - EW O'Rorke

44. RW Reid

45. GJ Rogers

46. WM Seeburger

47. RE Trumble

48. 300 File

49. File Copy

\section{INTRODUCTION}

The loss of cooling water from a Hanford production reactor has serious implications because of the accompanying reactivity transient. It is imperative that the time dependence of this transient be determined in order to evaluate properly some aspects of reactor safety. A previous experiment has been done (1) however it was primarily in the nature of an exploratory run leading to the present experiment. The experiments described below cover a much wider range of conditions and have been used as a basis for analog computations to determine the adequacy of the present safety systems from a response standpoint.

The water supply of a Hanford production reactor is well protected against most types of faults. One type of fault that cannot be accomodated in the supply system is an abrupt total rupture in the front face risers or in the immediately adjacent piping. It is this type of fault that will lead to the largest rapld increase of reactivity in a Hanford reactor. The previous experiment considered an 


\section{DECIASSIFIED}

$\mathrm{HW}-52340$

\section{INTRODUCTION (CONT'D)}

inlet pigtail rupture with suosequent water loss from both the inlet and outlet of the process tube. Project CG-5.58 provided check valves in all horizontal inlet crossheaders. The pigtail failure case is now valid only tor single tubes as the new check valves will prevent back flow in the case of a total failure of the water supply, the only case that is of serious consequence in regards to reactor safety. The present experiment was designed to investigate this type of fallure wherein the inlet is blocked on flow stoppage and the water expulsion can occur at the discharge end only.

This type of test would be very difficult to carry out in any manner other than a full size, full fower mock up. The Therma! Hydraulics Operation Laboratory provides a reasonable simulation of in-pile conditions, being capable of supplying both the coolant flow and the full proces: tube heat (electrically). The methods, equipment, procedure, and res.... wili be discussed in the following sections.

\section{SUMMARY}

The form of the reactivity transient assoniated with the loss of cooling water in a Hanford Production Reactor has been determined. The urve is presented as a function of integrated tube power after supply loss, see Figure 1. It is demonstrated that this transient, for the purposes of reactar safety analysis, is essentially independent of the previous process tube operating power level. Some explanation is offered as to the progress of the water out of the process tube.

\section{DISCUSSION}

1. - METHOD USED

The method used to determine the time distribution of the water in the process tube is an electrical capacitance measurement. The technique was demonstrated to be satisfactory in the initial experiments(1). The process tube and the active, heat generating, center rod (similar to an uranium charge in shape) are effectively a concentric cylindrical capacitor. The tube is the outer plate, the heater the inner plate, and the water the dielectric. Water has a hijh dielectric constant (of the order of 80 ) while steam acts as a gas with a constant near unity. The dielectric property of the cooling water will undergo a marked decrease as a boilout occurs. The magnitude of chare? in ihe capacitance of a section of process tube is then a measure of the quantity of water contained in it; the capacitance drops as steam is formed. This method permits high speed recording with a minimum of interference to the water ficw.

\section{2. - DESCRIPIION OF FACIIITTIES}

a - Piping

The Thermal Hydraulics Dperation Laboratory is a full scale mock up of a single process tube. This recirculating loop is diagrarnmed in Figure 2. The pump provides normal process tube inlet pressures and flows and also serves t.o pressurize the rear header to the proper degree by means of the valved bypass line. The cooling water is obtained as steam conaensate to minimize

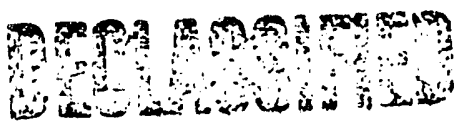




\section{DECLASSIFIED}

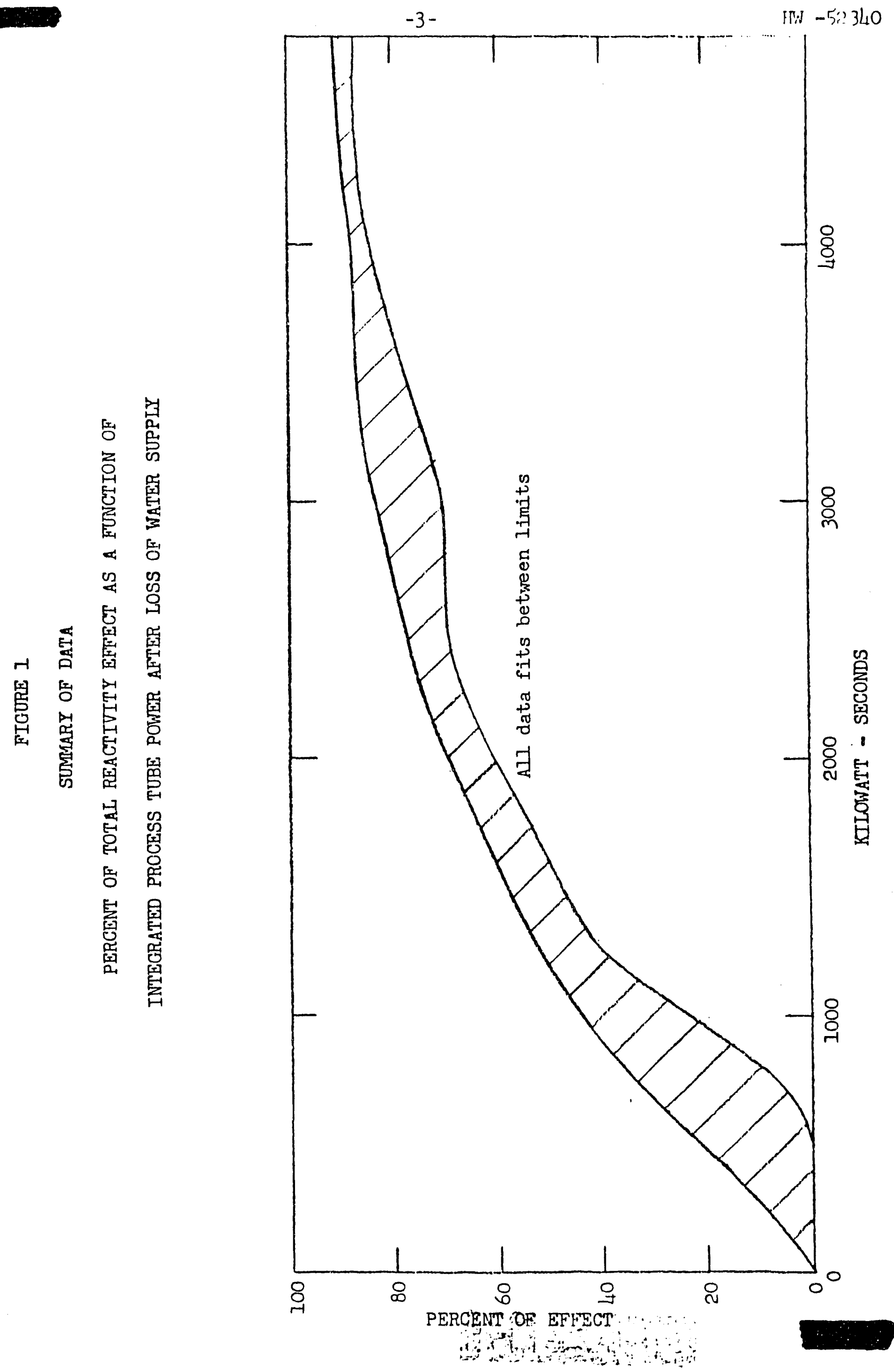


FIGURE 2

HYDRAULIC IOOP

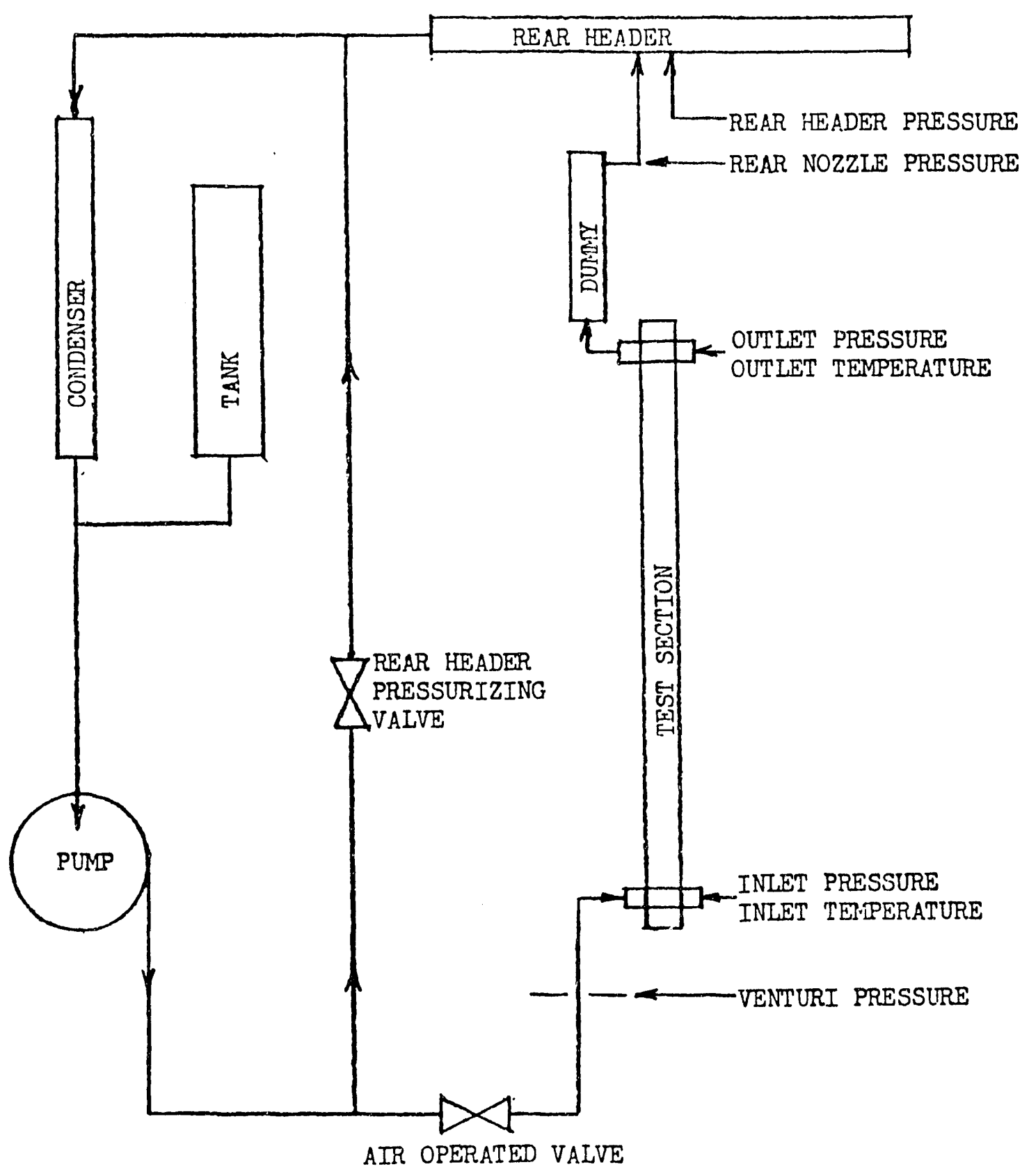


2. - DESCRIPTION OF FACIIITIES (CONT'D)

a - Piping (Cont'd)

corrosion and film buildup.

The water enters and leave the active test section by means 'of oversized annulus sections at each end. A short section of pipe couples the discharge end to the downstream dummy section. The annular flow is restored at the inlet, of the dummy section by means of a solid cone about four inches long. The remainder of the dummy charge is made up of standard perforated dummies. The rear fittings are standard on pile fittings to provide the proper flow resistances. The entire process tube section, dummy section, and rear fittings are all changed to convert from BDF to $C$ reactor flow conditions.

The water loss is simulated by means of the fast acting air operated valve in the water supply line. The motion of this valve is monitored by a switch which energizes an electrical timing signal to synchronize all recorders and to start the automatic shutdown of the heater power.

b - Power Source

The uranium charge is simulated by the electrical heater rod in the active zone. This zone is 24 feet long with water seals at each end to permit electrical connection to the heater. This rod is designed to simulate a cosine heat distribution by means of sections of different resistivity. These sections are made of several copper nickel alloys with various sized holes drilled in the center to adjust the resistivity. The overall rod has a heat capacity a bit larger than that for uranium. The diameter of the rod is slightly less than that of a canned slug. This is done to correct for the special coating inside of the process tube so as to maintain the proper cooling water annulus.

The electrical power for the heater rod is provided by three DC generators with an effective capacity of about $1300 \mathrm{KW}$. The fields of these generators can be controlled in such a manner as to simulate the fission heat decay in a reactor scram. The process tube power is measured by means of the volt - ampere output of the generators.

c - Process Tube

The active, heated zone process tube is made up of twelve electrically insulated two foot long sections. The sections are necessary to permit the water distribution to be measured by the electrical capacitance method. Two special short sections of standard gun barrel stock are on the outside of each piece of process tube to provide a means of coupling and to prevent possible

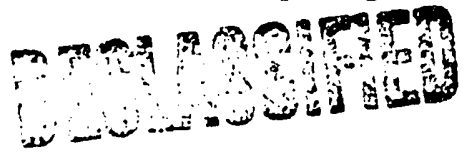




\section{SUMMARY (CONT'D)}

\section{DECLASSIFIED}

2. - DESCRIPTION OF FACILITIES (CONT'D)

c - Process Tube (Cont'd)

rupture of the tube. Vanstone flanges are applied to each end of the tube to supply a sealing surface. The entire inner surface of the tube section and the faces of the Vanstone flanges are coated with Heresite resin (2) to provide the necessary electrical insulation from the heater rod and adjacent sections.

The completed astive zone is made up by threading standard $\mathrm{BDF}$ flanges onto the gunbarrels, then bolting them together using insulating collars under the bolts (Figure 3). An asbestos gasket is used between the butted Vanstone flanges to provide a pressure seal as well as electrical insulation.

Sufficient sections are available to provide two complete test sections in each of the two sizes considered, $B D F$ and $C$ pile type. This provides sufficient spares to enable removal and replacement of damaged sections.

\section{d - Capacitive Instrumentation}

The sensing device which measures the change in capacitance is a series capacitive - inductive circuit, see Figure 4. A 600 rpm motor driven switch serves to place, separately, each of the sections into the circuit. By application of an alternating voltage to the circuit, any change in the capacitance of the section that is connected into the circuit may be measured by observing the corresponding change in the voltage drop across the inductor. The ifrequency of the alternating voltage was $5 \mathrm{KC}$. To record the data, the voltage across the inductor is applied to the vertical sweep of an oscilloscope. As the switch progressively samples the sections, a pattern of vertical lines or $\because \because \%$ is displayed on the scope. Each vertical line is representative of the magnitude of the capacitance in a particular section of the tube. The two $1 \mathrm{mfd}$ capacitors in the circuit serve to keep the system isolated from ground, and the standard capacitor provides a means of calibration.

A moving film, non framing, oscilloscope recording camera, Dumont type 321 , is used to record the oscilloscope pattern as the boilout progresses. A film transport rate of 400 inches per minute provides reasonable separation of the signal. An argon lamp is built into the camera to provide the time synchronization from the valve mounted switch. This signal is impressed on the film as a series of dots at the line frequency.

The correlation between capacitance and water content is very difficult to establish. The various possible modes of bolling can give considerably different calibrations. Some tests were performed in conjunction with the previous boilout experiment (I), and, on the basis of these a linear calibration of capacitance vs water content was assumed. Justification for this assumption may be found in the report on the previous experiment.
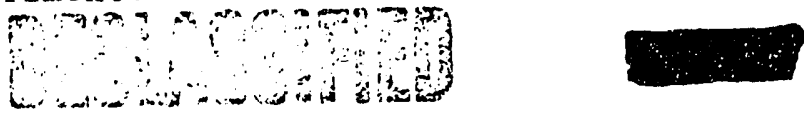


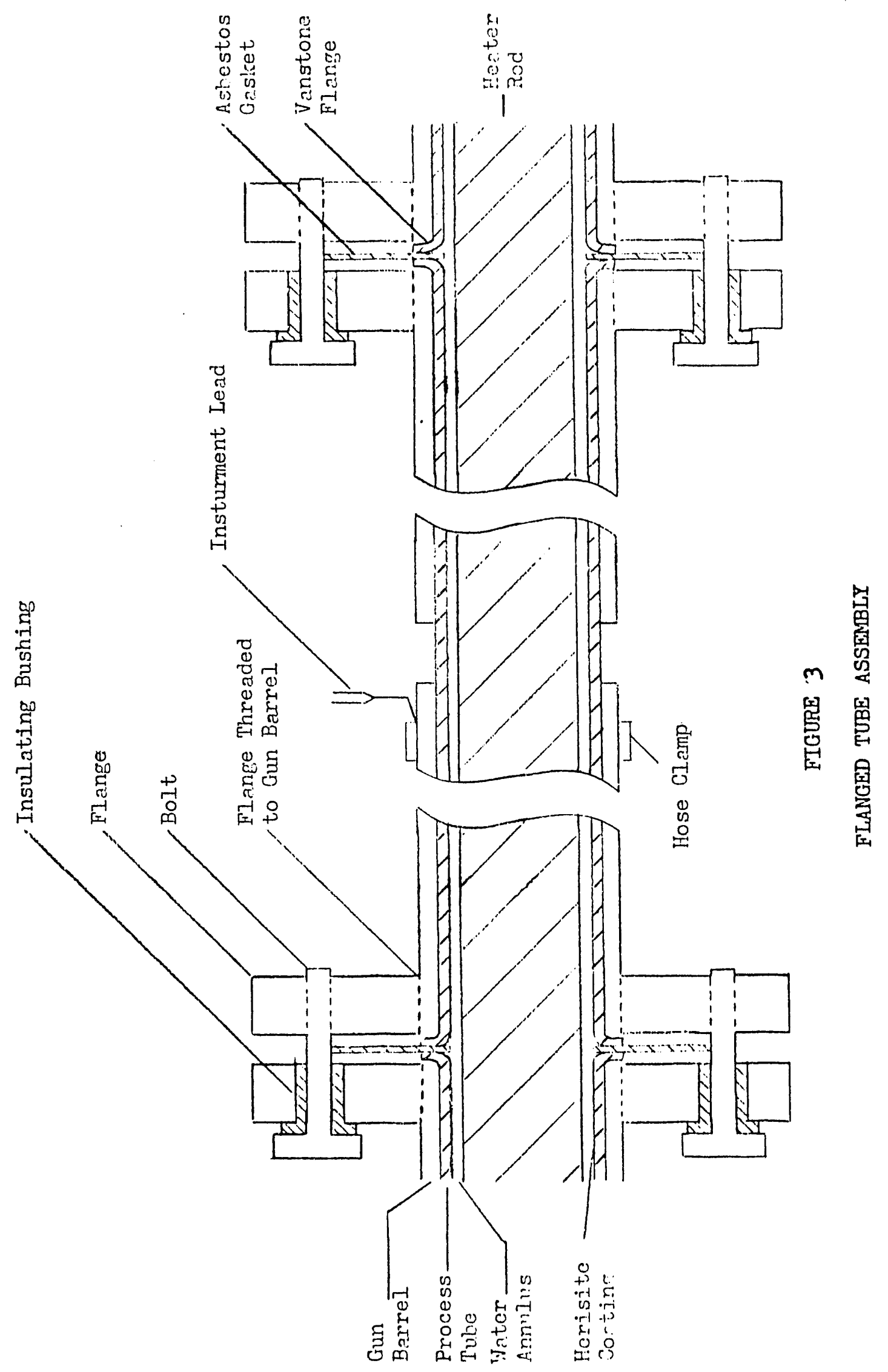




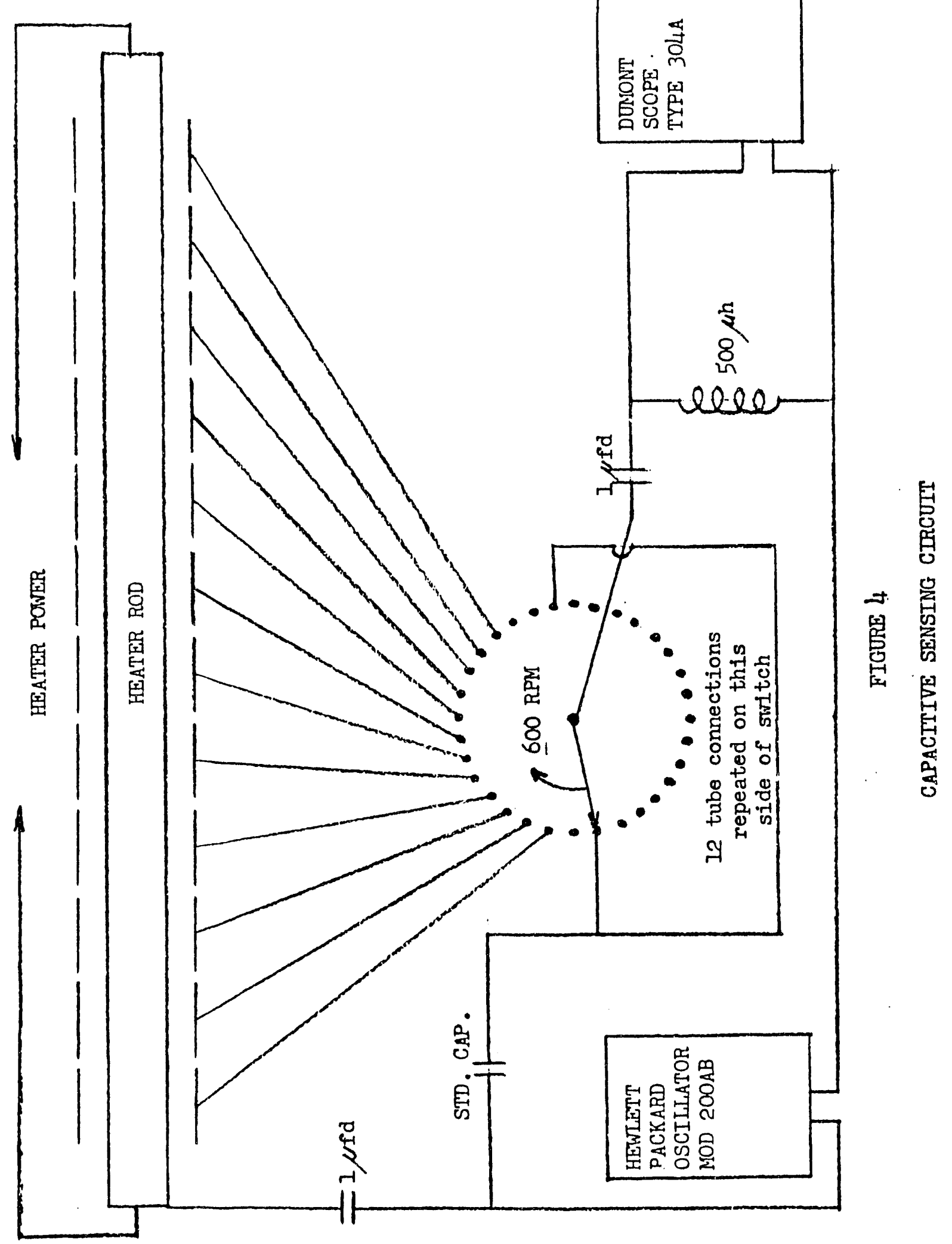


SUMMARY (CONT'D)

2. - DESCRIPTION OF FACILITIES (CONT'D)

e - Pressure Measurement

Special recording equipment is provided to obtain the pressure transients with accurate time resolution. High speed strain gauge type transducers measure the venturi throat and test section inlet and outlet pressures. Slower bourdon tube - potentiometer type transducers sense the pressure at the nozzle on the end of the dumy section and in the rear crossheader. These five elements are recorded on a Consolidated Electrodymamics Corporation oscilligraph. A timing channel provided the electrical time synchronization.

The equipment is calibrated by reading the pressures with a manifold and a Heise gauge while recording the steady state conditions on the oscillograph. This method provides both the pressurize reading and a zero reading.

The other pressures, temperatures, power, and flow are recorded on the normal installed equipment at the laboratory.

3. - PROCEDURE

At the start of each run, steady state conditions of power and flow are established and maintained. The flow conditions are as close as possible to in-reactor conditions although the pump used cannot quite attain the desired pressure. The conditions are read and noted just prior to initiating the transients. These readings are included in Table 1 for the runs utilized in this report.

A few seconds before the transient is to begin the recording equipment is put into action. This provides a steady state record. On a verbal order from the Engineer in charge the air operated valve is actuated cutting off the water supply to the test section, preventing back flow, energizing the electrical timing signals, and starting the cam determining the power decay. The decay cam used provides a three second delay followed by a reduction to ten percent of power in the next two seconds. The three second delay is selected to approximate the elapsed time until the on-pile pressure sensing equipment would act and the vertical safety rods would start to shut down the pile.

As the water boils out, the heat transfer from the rod drops sharply, this causes rapid rod heating which could lead to extensive damage if it is allowed to continue. To prevent, rod damage, the rod temperature recorder is visually monitored. If the temperature rises beyond a set point, a manual power cut is called for.

During the bollout tests two oscilloscopes were used. One of them was used in conjunction with the camera to provide a permanent set of data. The other was in parallel with the first, but was used only as a means of visuall: ronitoring the bollout. Observation of the transient allowed large savings in camera and oscillograph film by stopping the recorders when the boiling had reached a near steady state.

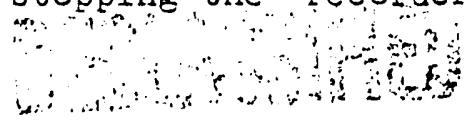




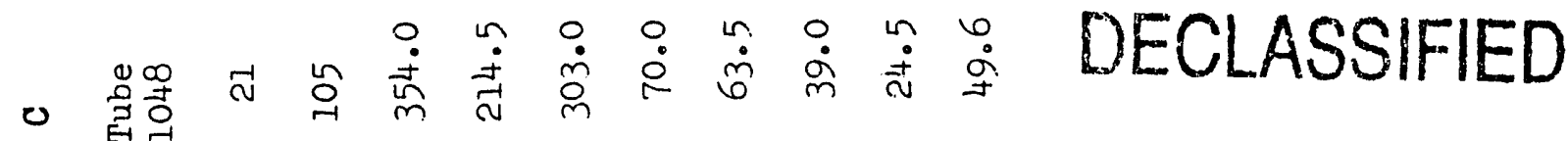

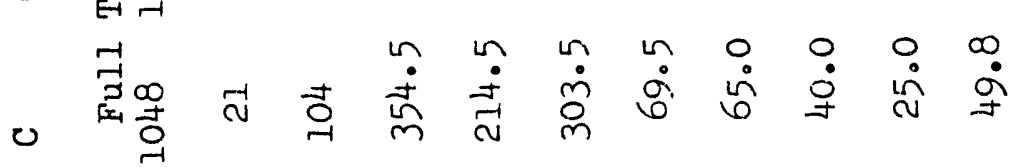

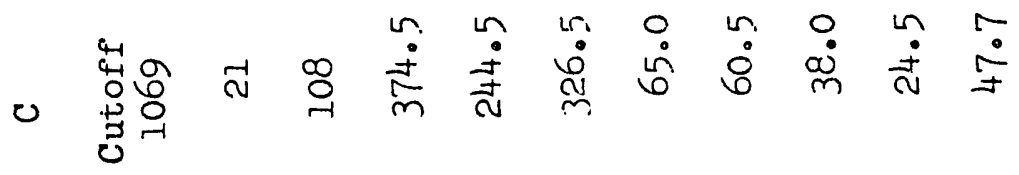

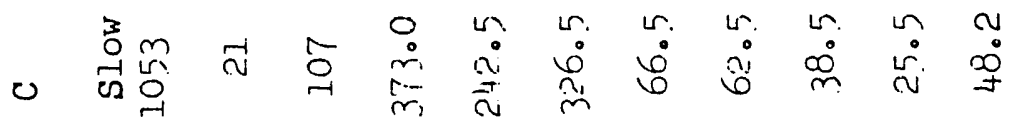

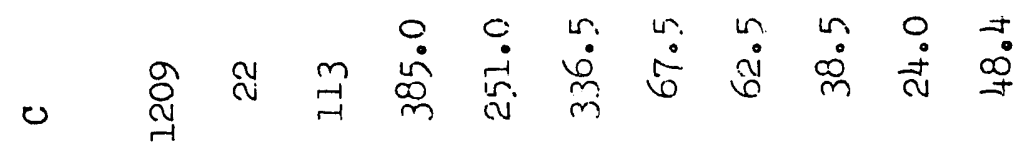

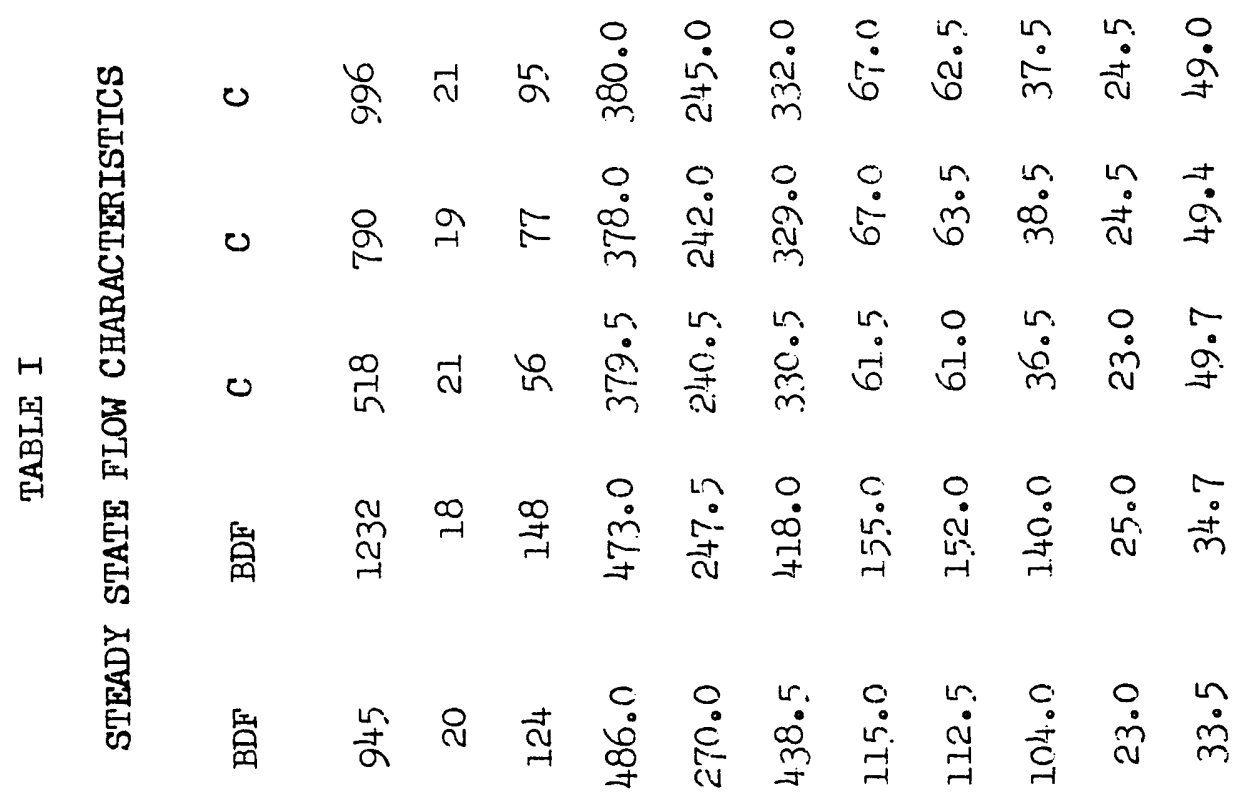

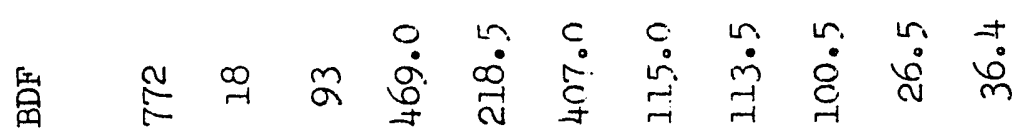

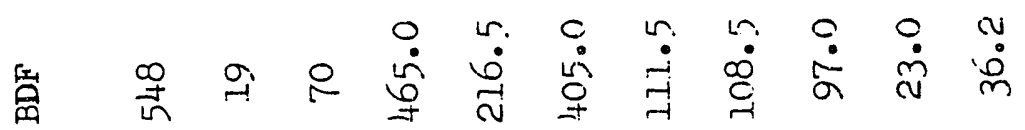

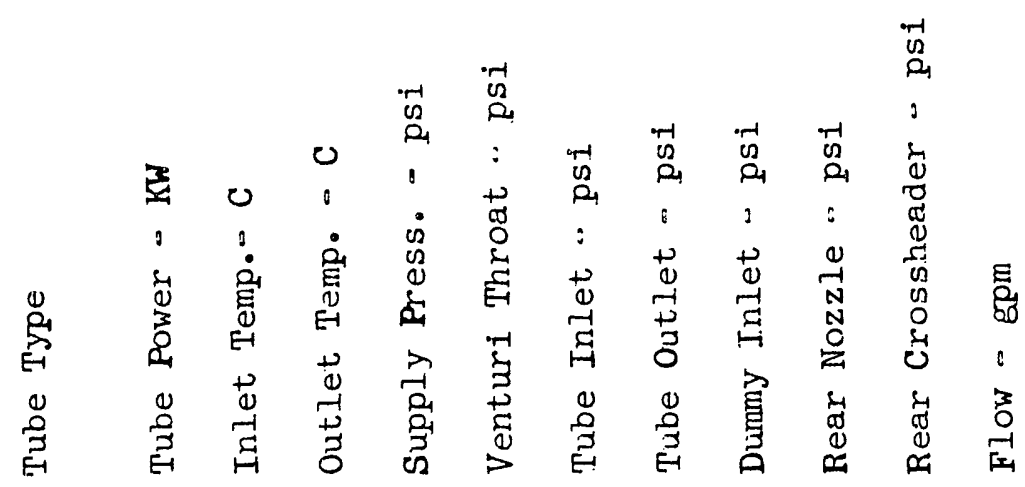




\section{SUMMARY (CONT'D)}

\section{DECLASSIFIED}

3. - PROCEDURE (CONT'D)

Four different tube powers were used for both BDF and $C$ size tubes. A complete log was maintained, and films were photographically numbered while in the camera, thus eliminating the possibility of a film mixup. To make sure of getting one good run, at least three transients were run at each powtr level.

The filmed capacitance data were reduced by developing the film and tabulating the data as read from an enlarging type viever equipped with a calibrated scale. All data reading was done by the jame observer to keep errors constant, although undetermined. The reading, were then converted to percent water content by taking the maximum value for each section as 100 percent and using a linear calibration. Interpolation was then made for the finite time in each scan to obtain tables of percent content vs time for a uniform set of tine increments. These data were then plotted to obtain the spatial water distribution vs time and integrated to obtain total water content vs time. These curves are appended to this report for informational purposes as Figures 7 through 29.

$\underline{\text { RESULTS }}$

1. - SCOPE OF THE TESTS

A total of 34 experimental runs were made. Of these 16 were with BDF type process tube at nominal powers of $500,750,1000$, and $1250 \mathrm{KW}$, 12 were with $C$ type process tube at the same powers, 4 were with $C$ process tube at, $1000 \mathrm{KW}$ and with a slow (about $1 \mathrm{sec}$ ) water cutoff, and 2 were with $\mathrm{C}$ process tube at $1000 \mathrm{KW}$ and a full, unsectioned process tube. One run at each power for both BDF and $C$ type tubes, two of the slow cutoff, and both full tube tests (a total of 12 runs) were selected for further treatment. The bases for selection were complete data and uniform conditions.

The air operated valve is very rapid, providing complete flow stoppage in a few hundreths of a second. This action is faster than any event that can be.postulated on pile so several runs were included in a $C$ type tube with shutoff times of from 0.5 to 1 second as obtained from the rapid closure of a manual valve. Two runs are also included on a full, unsegmented $C$ type tube to check for severe error in pressures and flow restriction due to the segmented tube.

2. - WATER REMAINING IN TUBE

A significant feature of the curves of water distribution and total water volume in the tube at different times during the tests (see Figures 7 through 19) is that in no case did the tube boil completely clear of water in the course of the experiments. The boiling started downstream of the center and proceeded in both directions. The point of onset of boilin. moved further downstream upon increasing tube powers. The nature of the bciling in the upstream half of the tube appears as a somewhat burping type with indeterminant slugs of water belng blown downstream. The onset of the boting in the BDF tube varied from one second in the $500 \mathrm{KW}$ case to instantaneous in the 1000 and 1250 casesm All boiling in the $C$ tube occurred Immediately upon stoppage of the water law 
RESULTS (CONT'D)

\section{DECLASSIFIED}

2. - WATER REMAINING IN TUBE (CONT'D)

The slower cutoff cases for the $C$ tube at $1000 \mathrm{KW}$ display transients very similar to the instantaneous case with the exception that the time is effectively displaced. The curves colncide if the zero time is taken at about the half flow polnt. It is not known how long a time delay this fact will hold for but it appears to be a useful approach for evaluation of any studies of the rupture time of the valve pit pipling.

\section{3. - DETERMINATION OF REACTIVITY EFFECT}

The datawere further reduced to obtain the form of the reactivity transients for use in reactor safety analysis. The previous time dependent spatial water distribution curves were given a cosine squared weighting for each process tube section to correct for the position dependence of reactivity. The resulting values were then integrated and normalized to yield the percent effect of the total possible reactivity translent: The reactivity transient is plotted vs integrated $\mathrm{KW}$ seconds in Figures 5 and 6 . The integrated power is obtained from the power level recorder, and, as such, is corrected for the power decay.

The significant feature of these curves is the fact that the reactivity transient is predominately a function of integrated power, and the equilibriur: tube power before water loss has little effect. A further feature is that the $B D F$ and $C$ curves coincide within the accuracy of the data. The prime difference among the curves at different power levels is that an Initial divergence is observed as a function of original tube power. This divergence rapldiy disappears, and all curves agree above $1200 \mathrm{KW}$ seconds in the BDF case and $1400 \mathrm{KW}$ seconds in the C case.

\section{4. - ANALYSIS OF OBSERVED PRESSURES}

Analysis of the pressure transients offers some explanation of the effects observed. The pressure transients were read at fixed time intervals and converted into pounds per square inch. The pressure drop across the three major sections of interest, the test section, the dummy section, and the rear fittings, was then determined by means of the differences between the pressure readings on each side of the section. There is some error in this technique as the pressure instrumentation was not set up or calibrated with this use in mind, however the trends are indicative of the transient processes involved. These curves are plotted vs $\mathrm{KW}$ seconds in Figures 20 thru 31. The BDF cases show significant pressurization in the rear fittings at the time of convergency of the reactivity transients. This pressurization becomes quile sharp as the tube power is increased. The $C$ data are not as pronounced although it follows simiiar trends.

The two standard $C$ tube runs, Figures 30 and 31 show less pressurialtion in the process tube and more in the dummy section and rear fittings when compared to the segmented experimental tube at a similar power, figure 26. This is evidence that the segmenting of the prcress tube provided something similar to a small distributed orificing effect along the test section and required higher pressures to accomplish the water flow under transient conditions. Ths sould imply that the real, unsegmented case would suffer

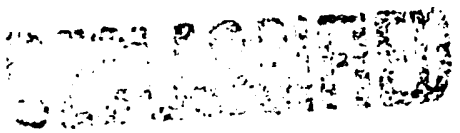




\section{DECLASSIFIED}
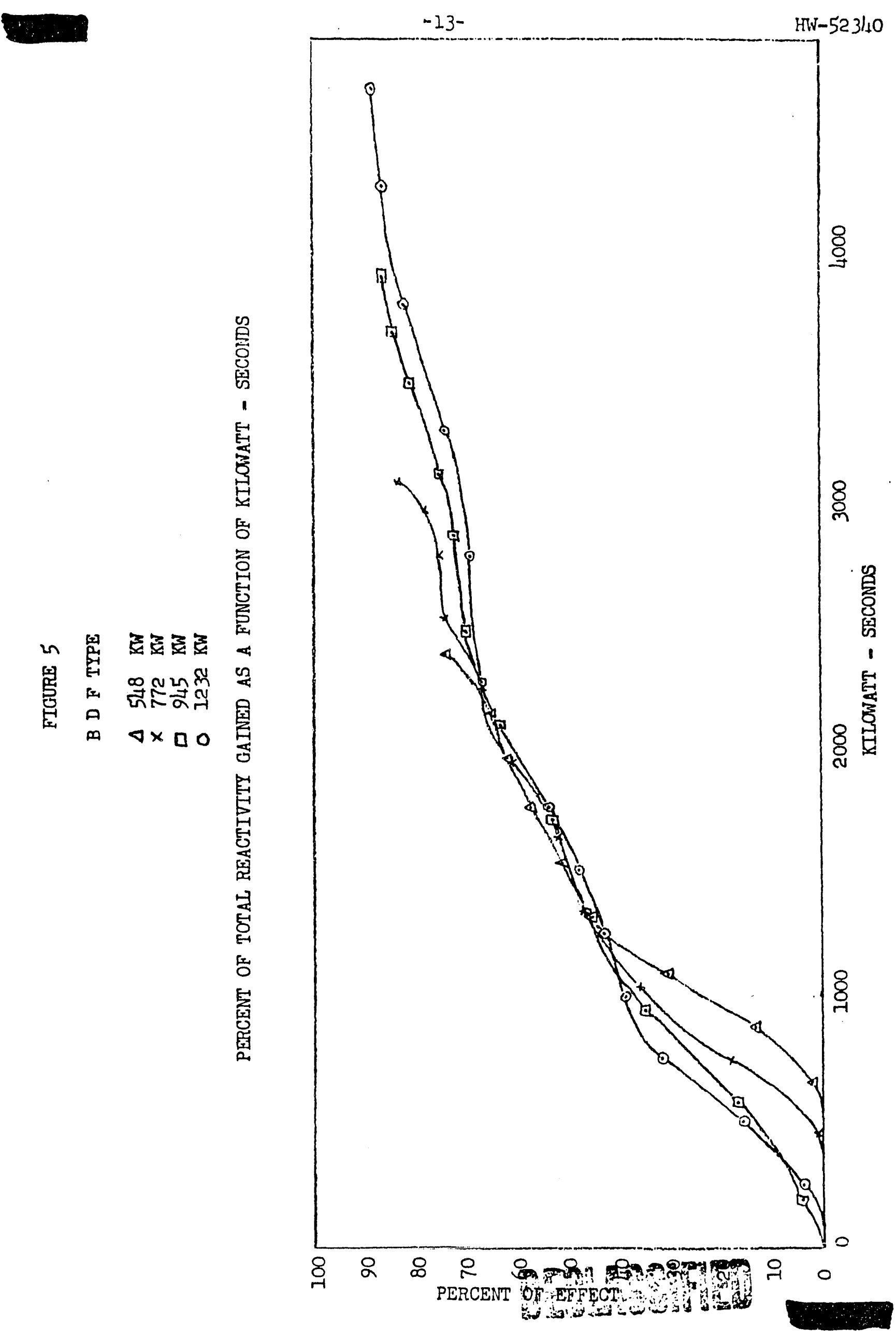


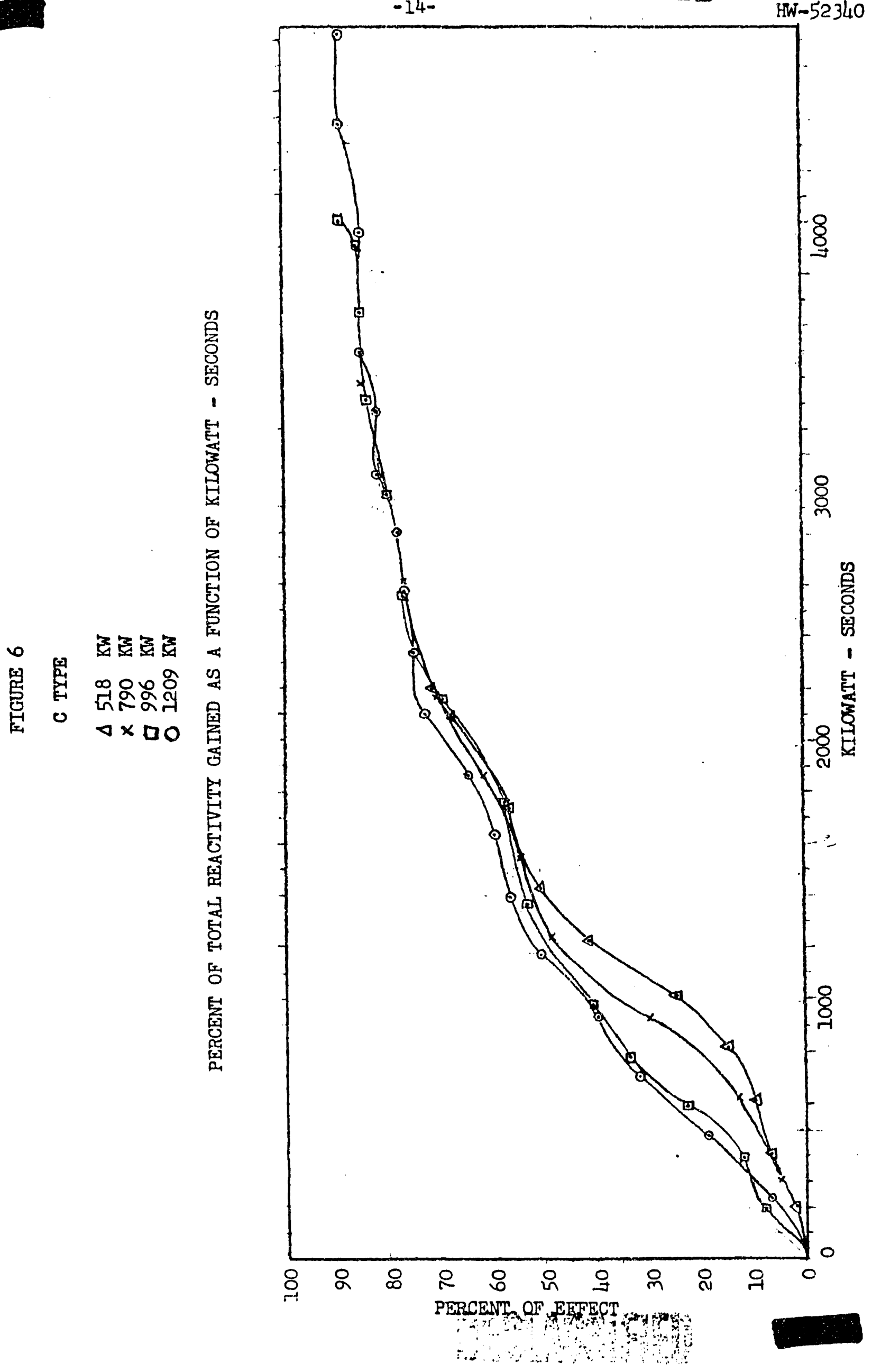




\section{UELLASSIFIED}

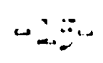

RESULTS (CONT'D)

4. - ANALYSIS OF OBSERVED FRESSURE (CONT 'D)

a more rapid transient than demonstrated. This is compensated to a degree by the requirement for higher pressurization in the downstream sections to accomplish this flow. Insufficient data are avallable at the present to evaluate this effect, and the reactivity transients must be accepted at face value. The effect of the tube segmenting is attributed to the asbestos gaskets used; these gaskets underwent some plastic flow due to the pressure exerted by the flanged connections. Any future experiments of this nature should have this effect removed through redesign of the gasketing system.

A volumetric flow analysis: $3:$ of the transient conditions in the downstream piping was carried out on the $945 \mathrm{KW}$ BDF run. This was based upon the transient pressure records and the steady state hydraulic flow characteristics of the piping downstream from the test section. It was assumed that there was some type of steam-water interface which progressed along the downstream piping during the boilout. The analysis indicates that the outlet of the test section is cleared of solid or near solld water flow at about the time ( $1100 \mathrm{kw}-\mathrm{sec}$ ) of the first peak in the test section delta pressure transient in figure 26 . The onset of appreciable steam flow causes the resistance to flow to decrease. The return to a rising delta pressure is attributed to a mixed water-steam flow at the test section outlet rather than pure steam. The second peak near $2100 \mathrm{KW}$ seconds correlates to a reasonable degree with the emergence of steam at the rear nozzle.

The flow of water in the BDF pigtail and its fittings is limited by cavitation above a pressure differential of about 60 psi. This means that the flow is constant from 1700 to $2200 \mathrm{kw}$ seconds. The minimum in pigtail pressure drop at $2450 \mathrm{kw}$ seconds is associated with the emergence of steam into the rear crossheader, and the ensuing rise unt1l $2900 \mathrm{KW}$ seconds must be due to steam-water mixtures rapidly driven by the expansion resulting from the decreasing absolute pressure within the process tube.

This type of analysis was not extended to the other experimental transients. It is believed that the characteristic double humps observed in the test section pressure differentials is adequately explained by this analysis and that the explanation applies to all tests.

The water volume in the dumy section appears to be the determining factor as to when and how large the differential pressure peak in the test section is. The experimental test mockup had to include close to 20 per cent more volume in the downstream piping because of the necessary connections to permit access to the end of the heater rod. The smaller volume of the real in pile case would tend to make the peak occur sooner. It is concluded, on the basis of the rather smooth reactivity transients in this region, that this volume error will not appreciably affect the reactivity data.

The crossheader pressure transducer became inoperative during the tests on the $C$ process tube. This pressure was assumed to be constant at the equilibrium value in order to obtain the pigtail pressure differentials in all runs except the two full tube tests, when the transducer was again operative. The error is estimated to be less than 8 psi.
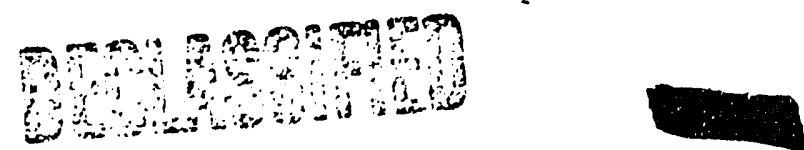


\section{DECLASSIFIED}

HW -52340

RESULTS (CONT'D)

4. - ANALYSIS OF' OBSERVED PRESSURE (CONT 'D)

One effect that could not be simulated during the transient tests is the possible pressurization of the rear crossheader due to other process tubes. This effect should not be very large as the pressures maintained through the bypass line are those hat result from the effect of the other tubes during normal operation. The onset of critical flows during the transients will prevent the total rear crossheader flow from becoming appreciably larger than normal hence the rear pressurization would not be much greater in the full pile case.

\section{CONCLUSIONS}

The reactivity transient associated w1 th complete and rapid stoppage of cooling water supply to a reactor has been determined to an accuracy sufficient to permit its use in reactor safety determinations. This transient in terms of integrated power is essentially independent of individual process tube power, and a single curve, with proper normalization for total inhour value, can be employed for analysis of $B$, $D, F, D R, H$, or $C$ reactors .

\section{ACKNOWLEDGEMENTS}

The authors are indebted to the Thermal Hydraulics Operation of the Hanford Laboratories and in particular to $\mathrm{W}$. L. Thorne, who procured the special process tubes and operated the Heat Transfer Facility. R. R. Cone of the Instrument Development Operation provided and set up the special pressure sensing equipment.

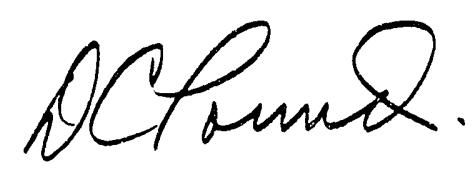

Reactor Physics

Research and Engineering IRRADIATION PROCESSING DEPARTMENT

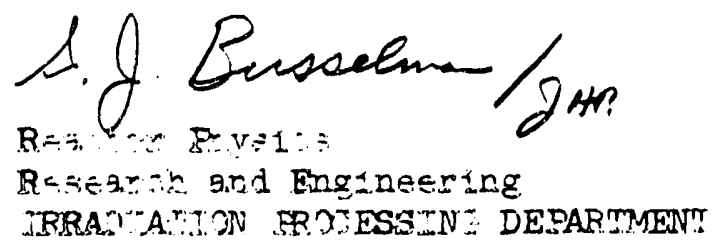

DC Bund: Gi: B.ssemanat ir. 


\section{REFFRENCES}

1. D. C. Pound, Boilout Experiment, HW-48759, February 27, 1957, Secret.

2. Heresite and Chemical Company

3. J.A. Roberson, Private Communication.

\section{DECLASSIFIED}



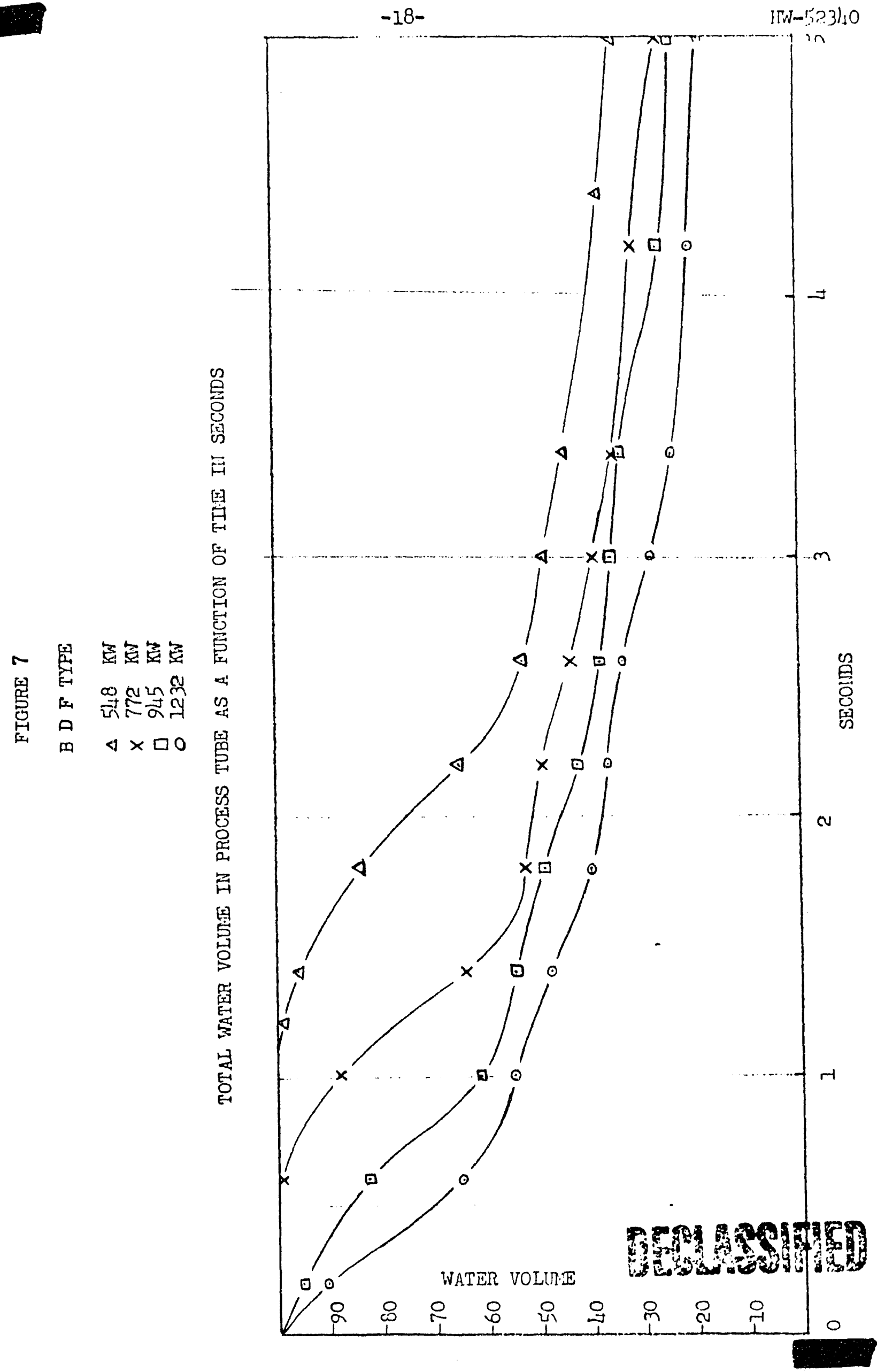


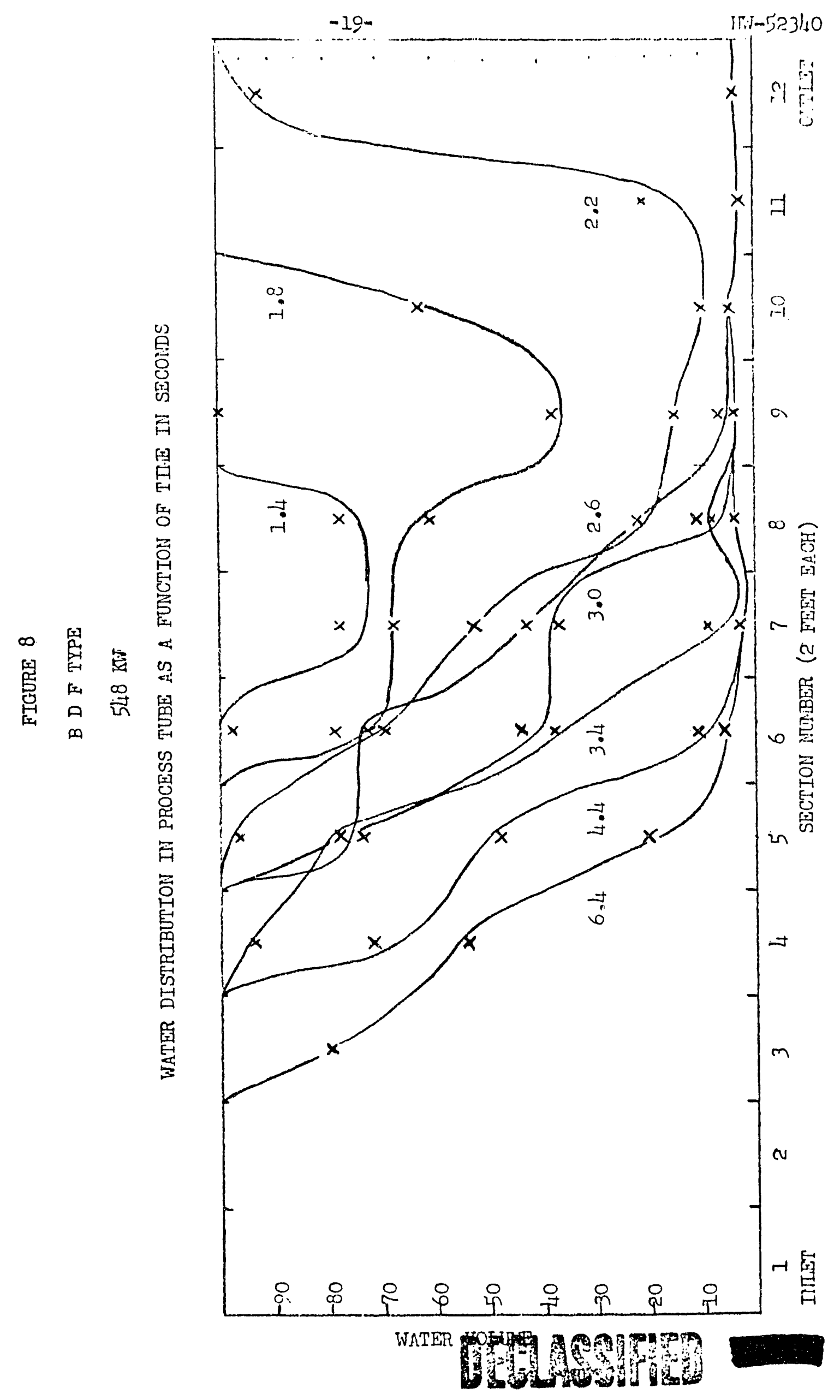




\section{DECLASSIFIED}

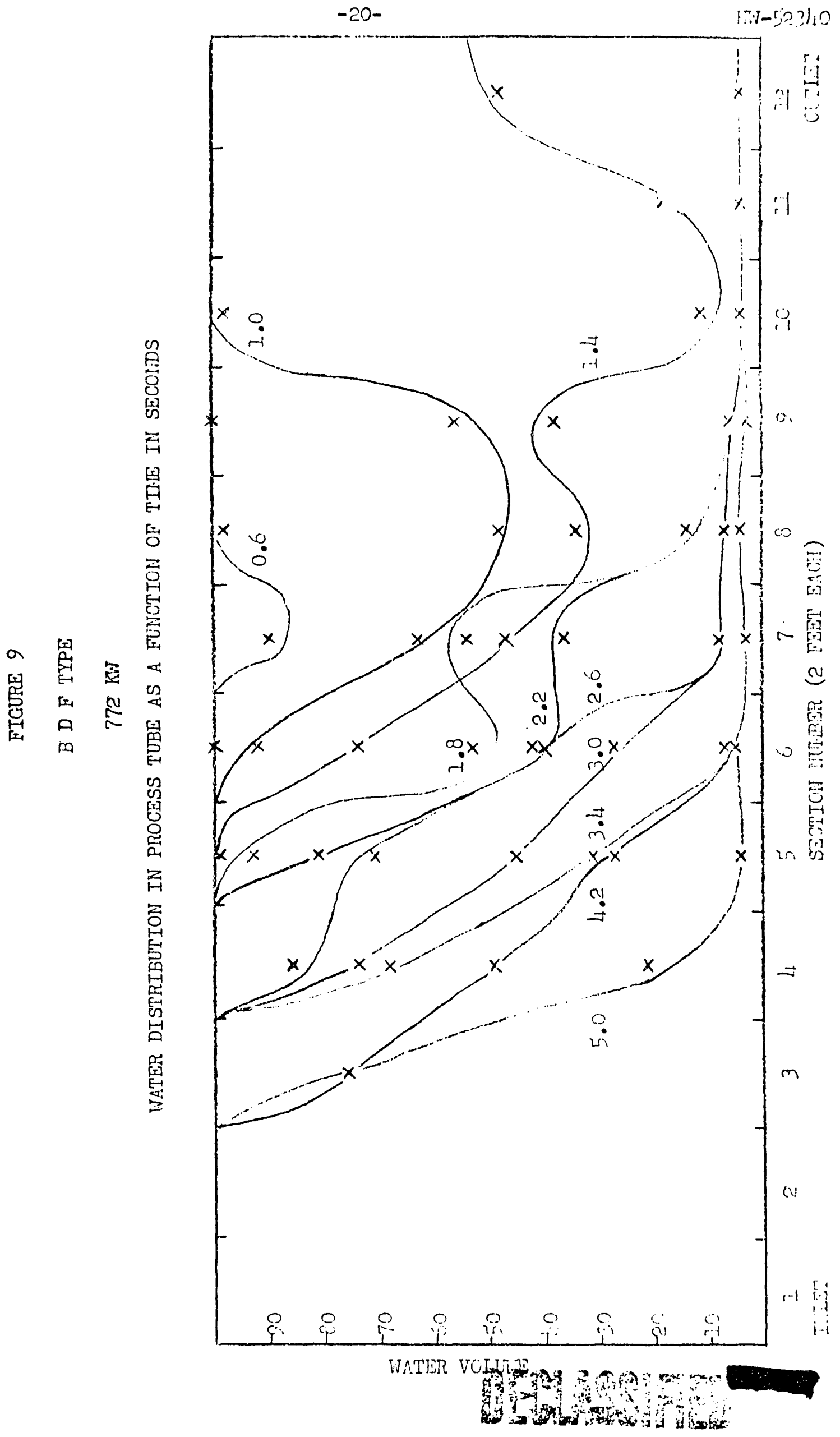




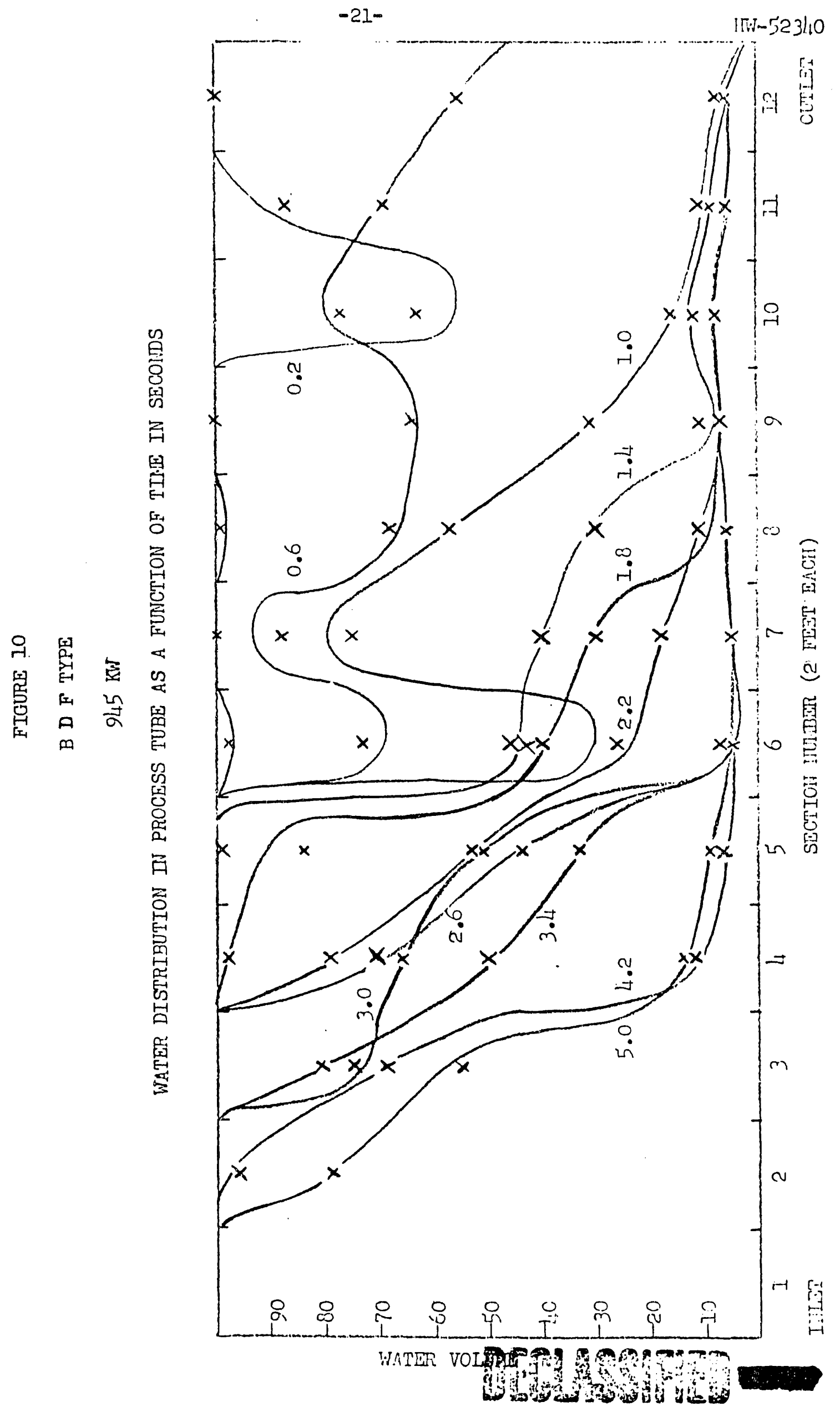


DECLASSIFIED

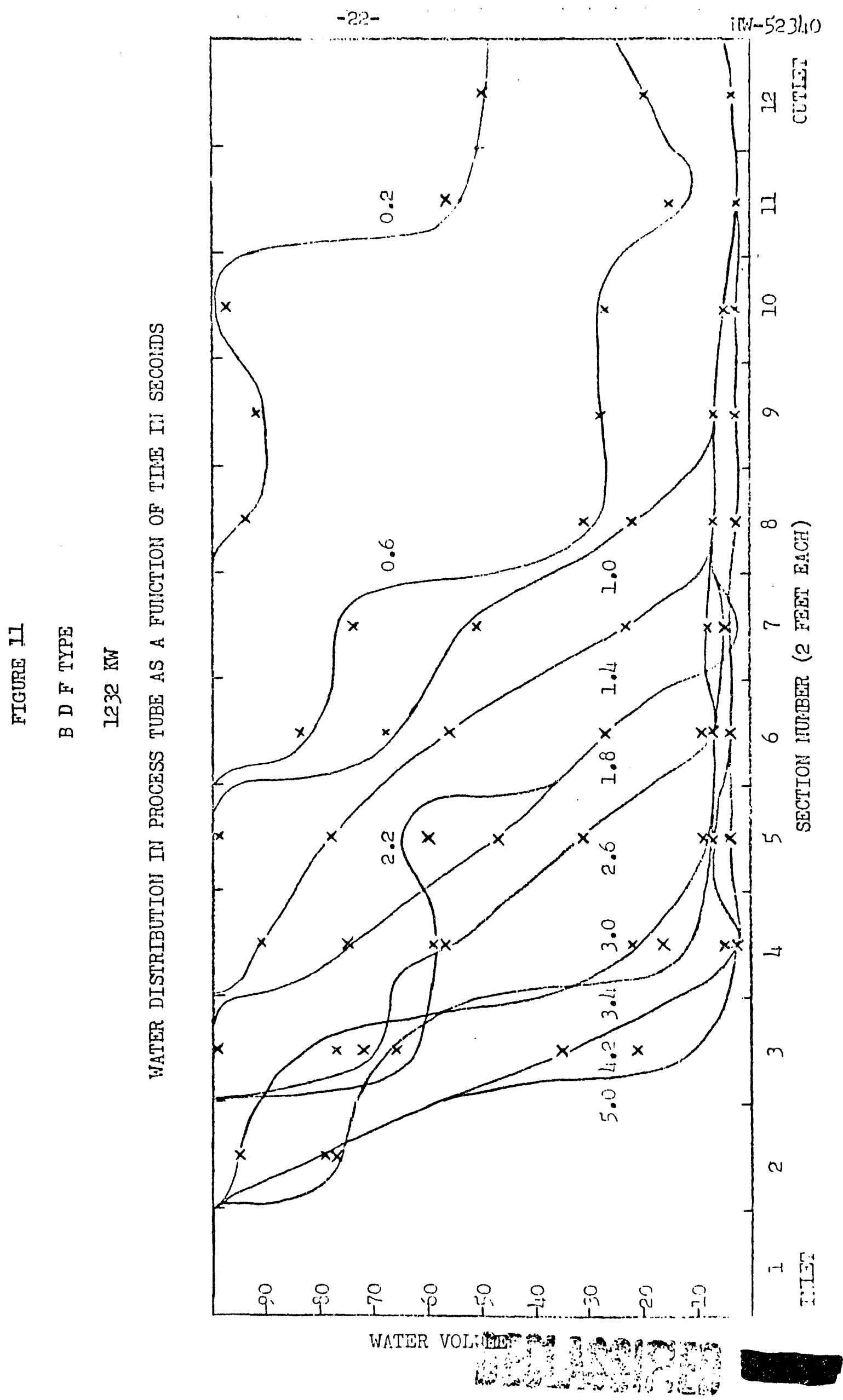




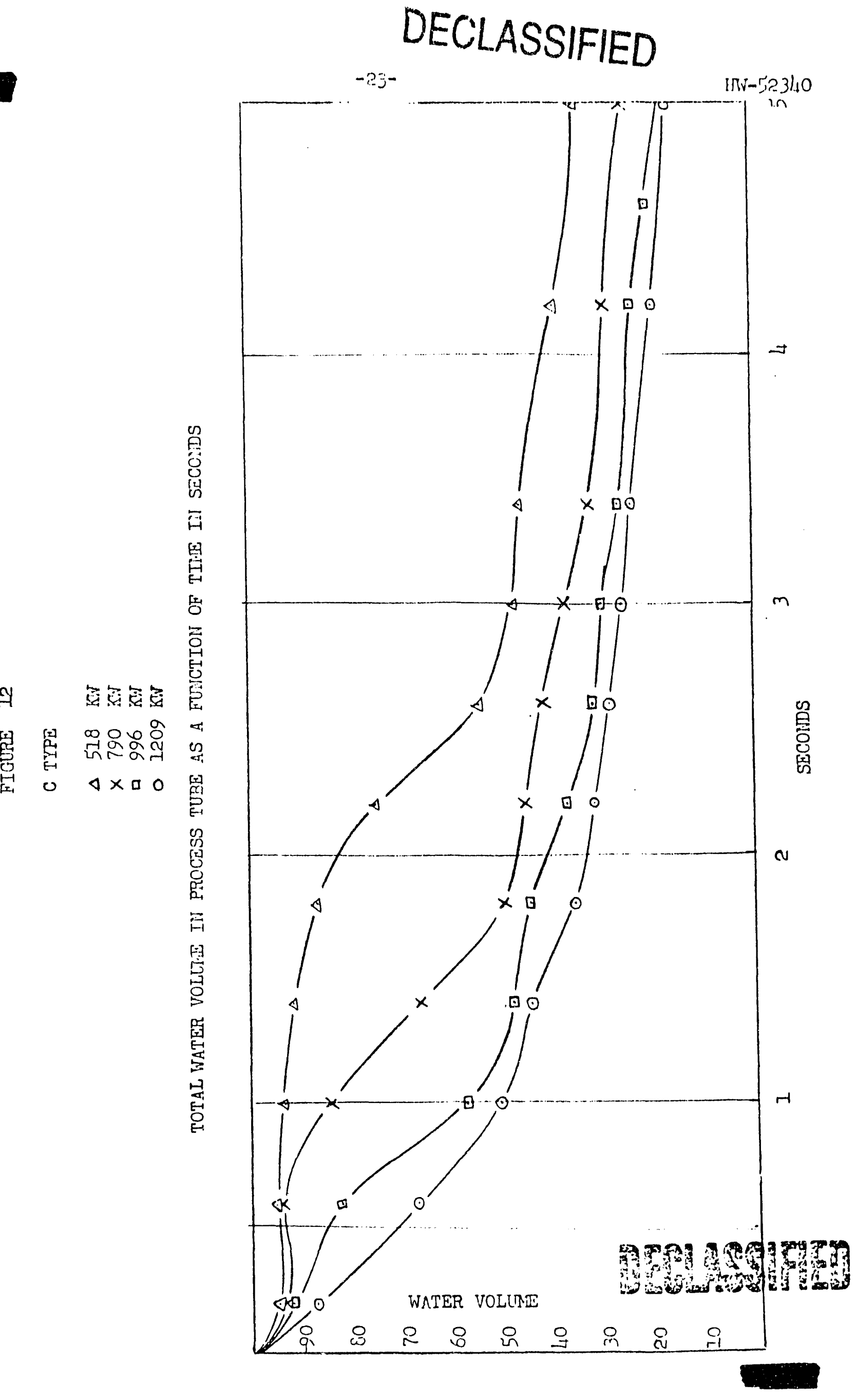


DECLASSIFIED

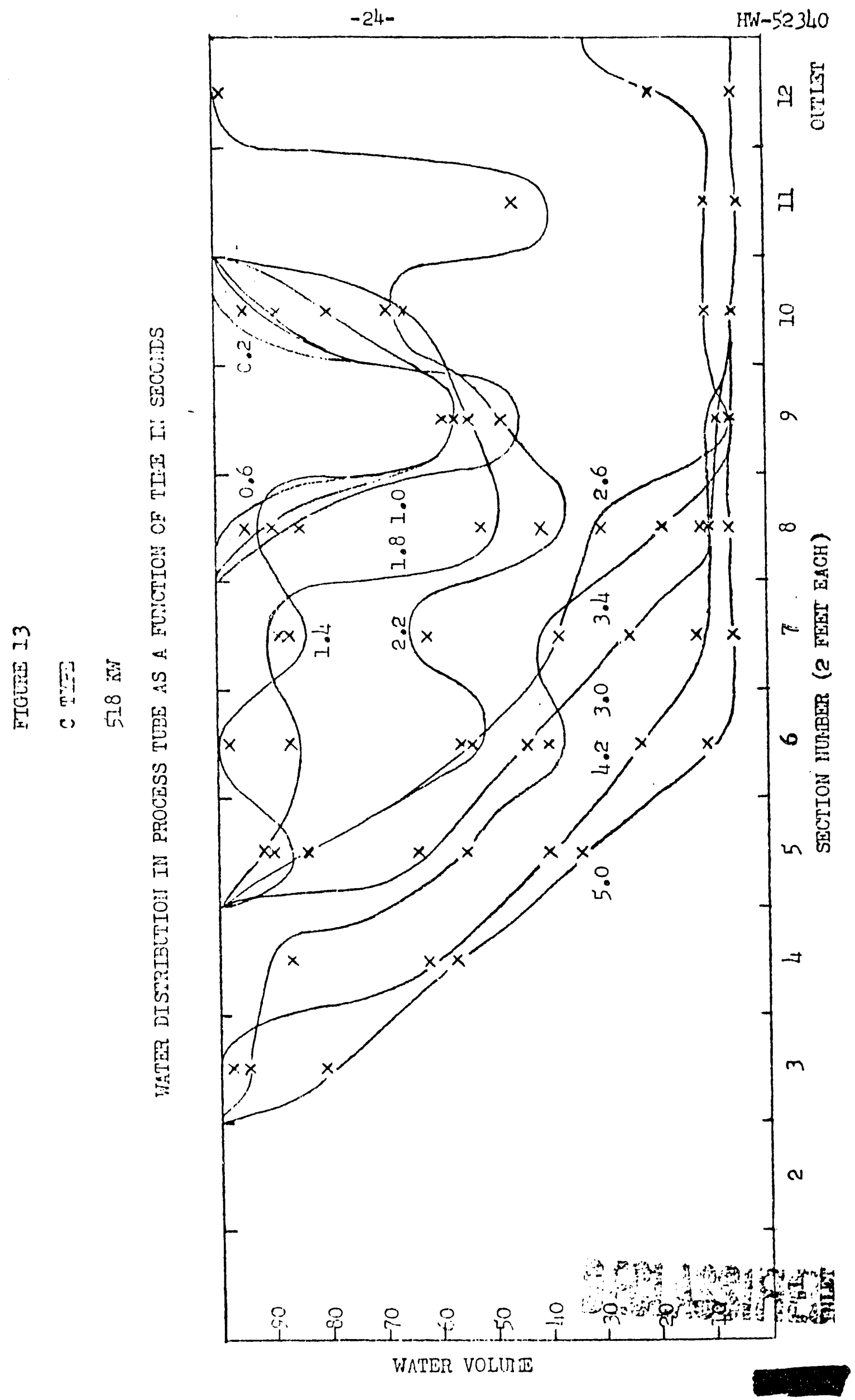




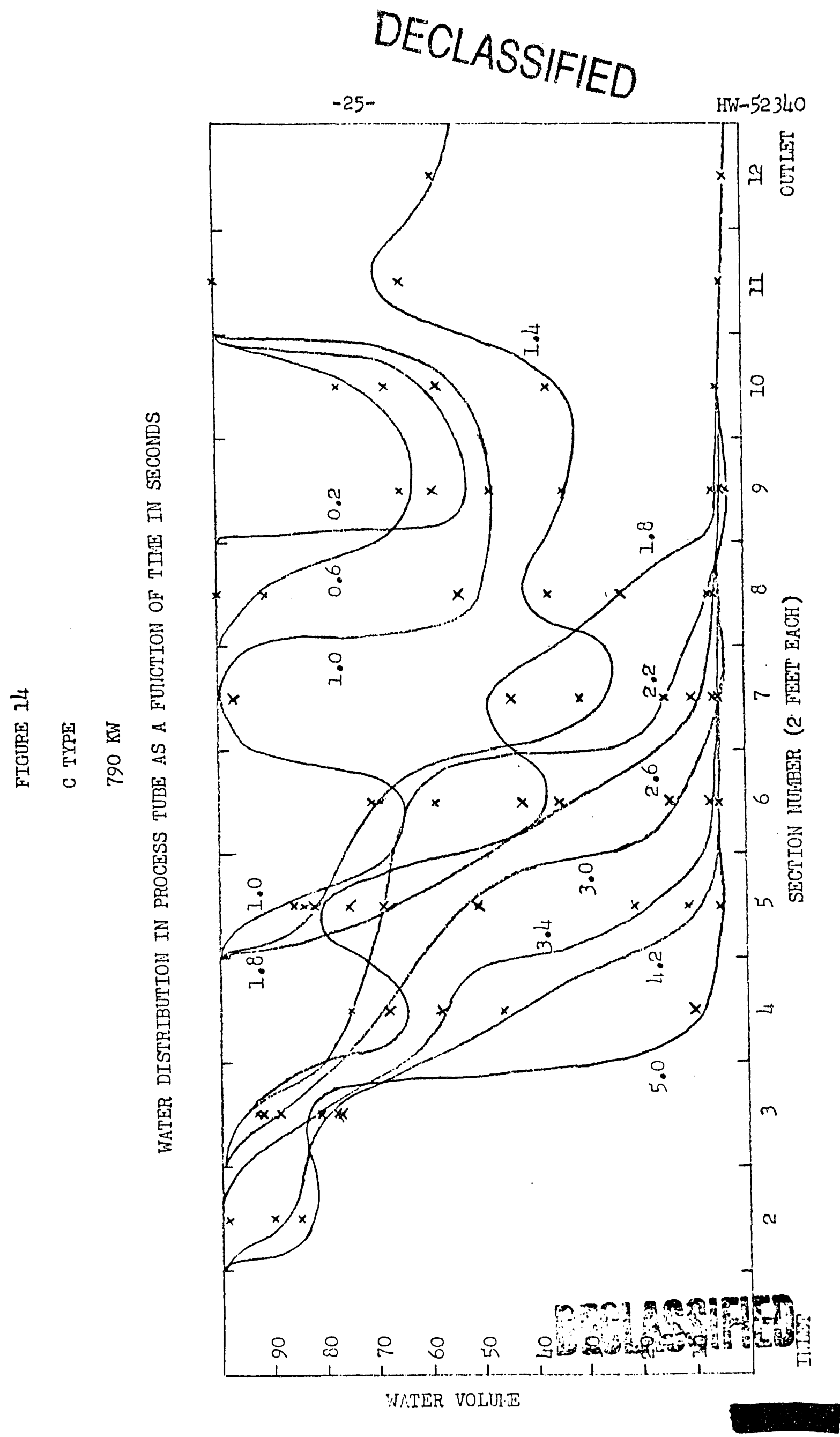




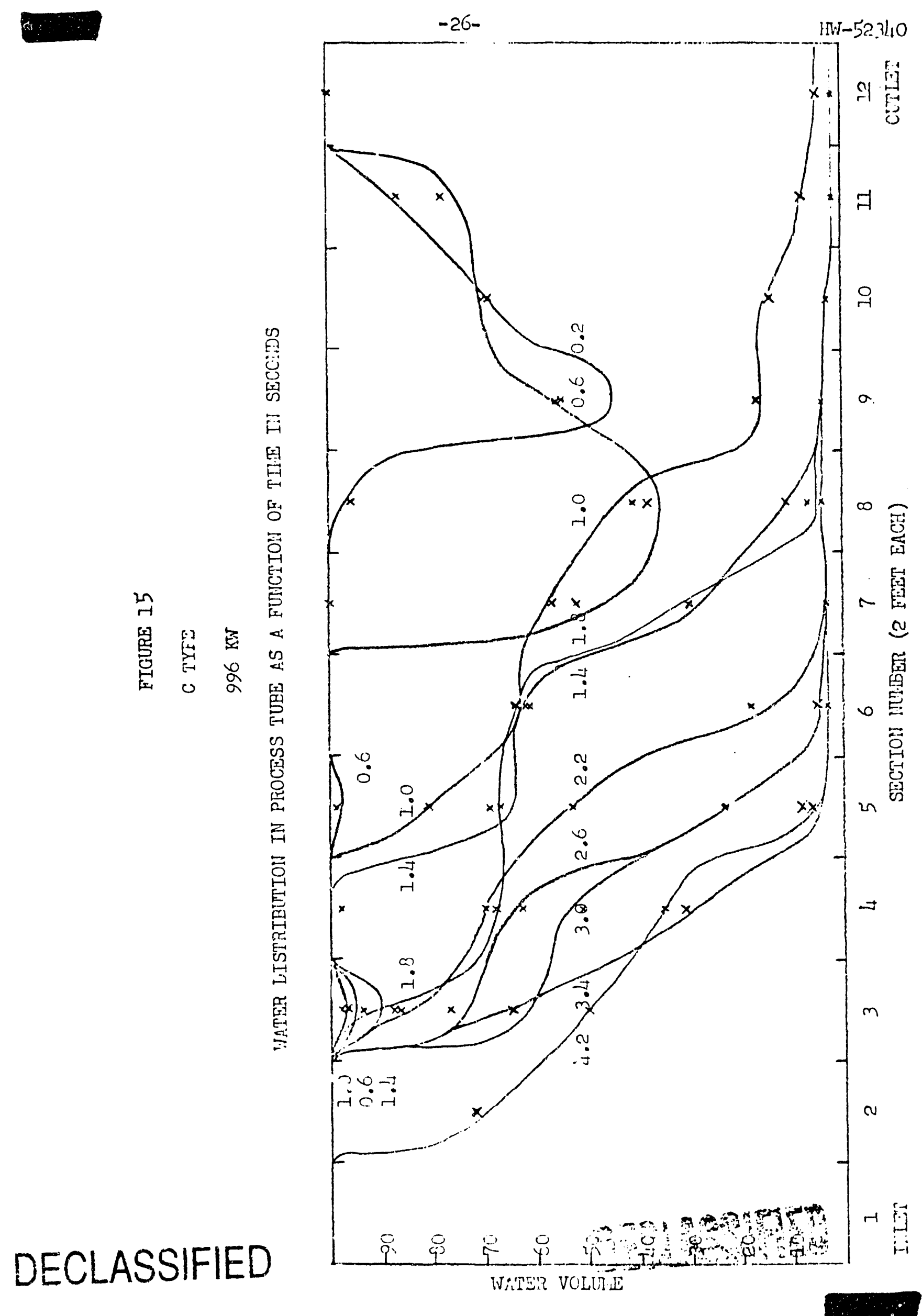




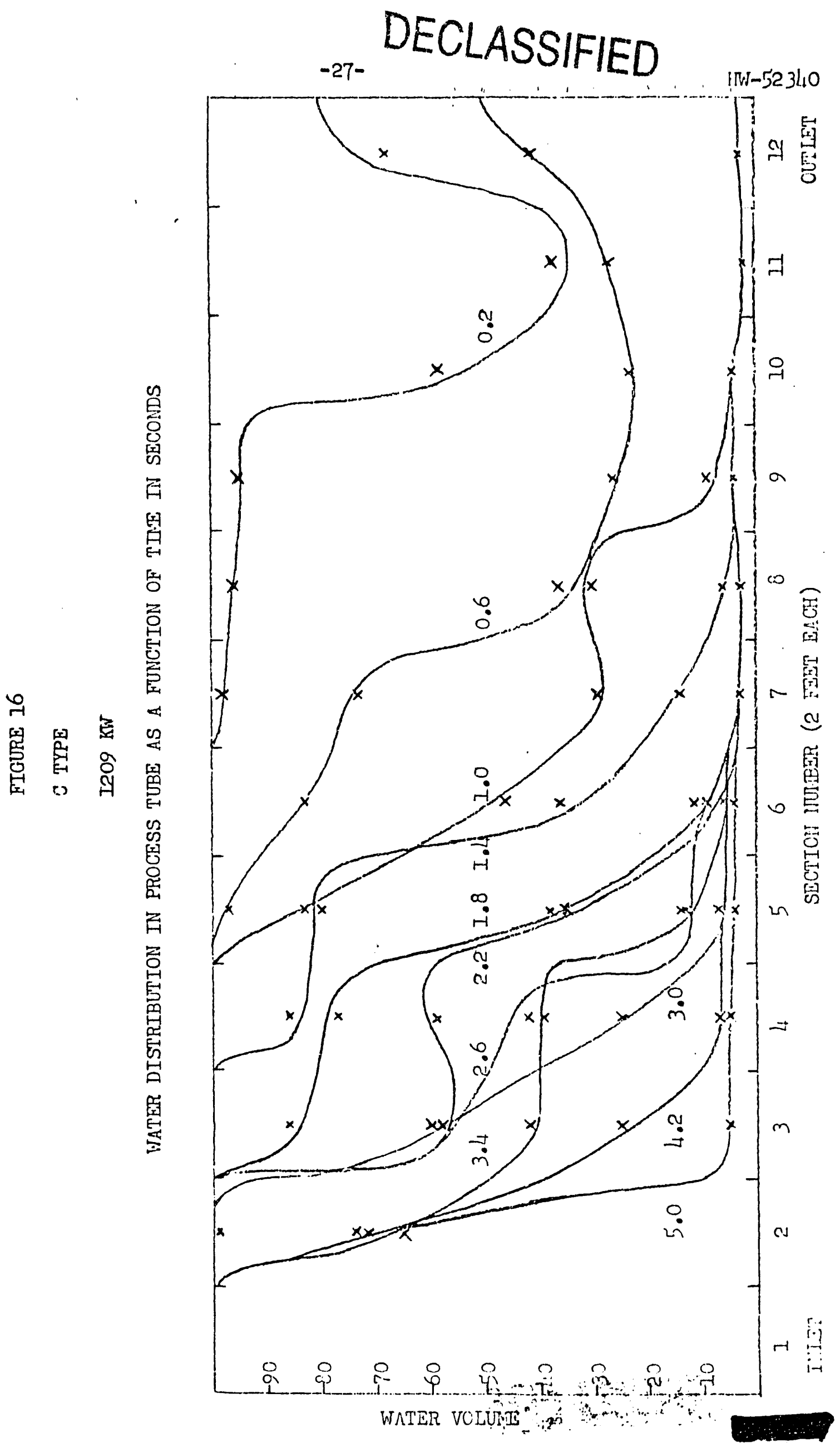




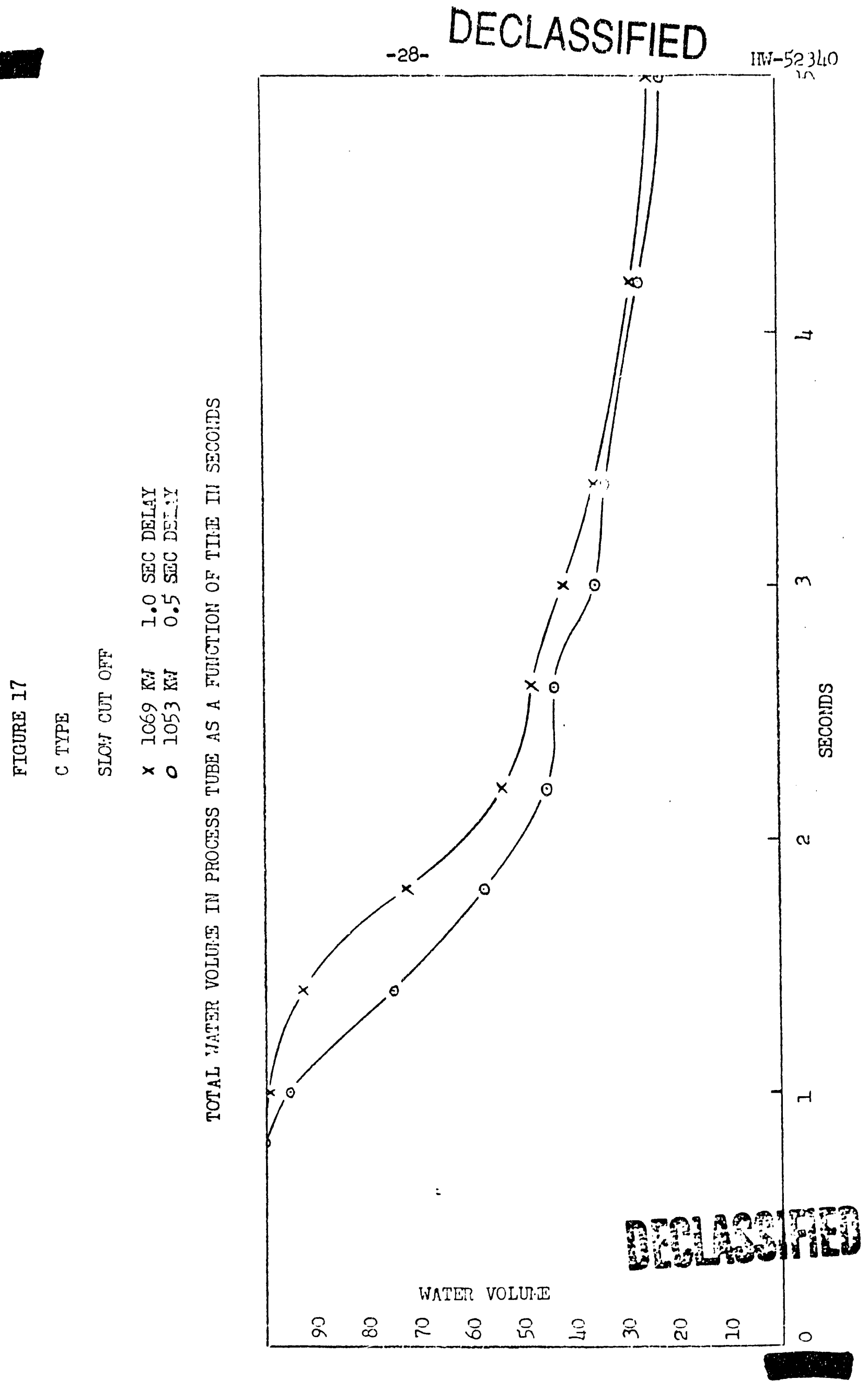




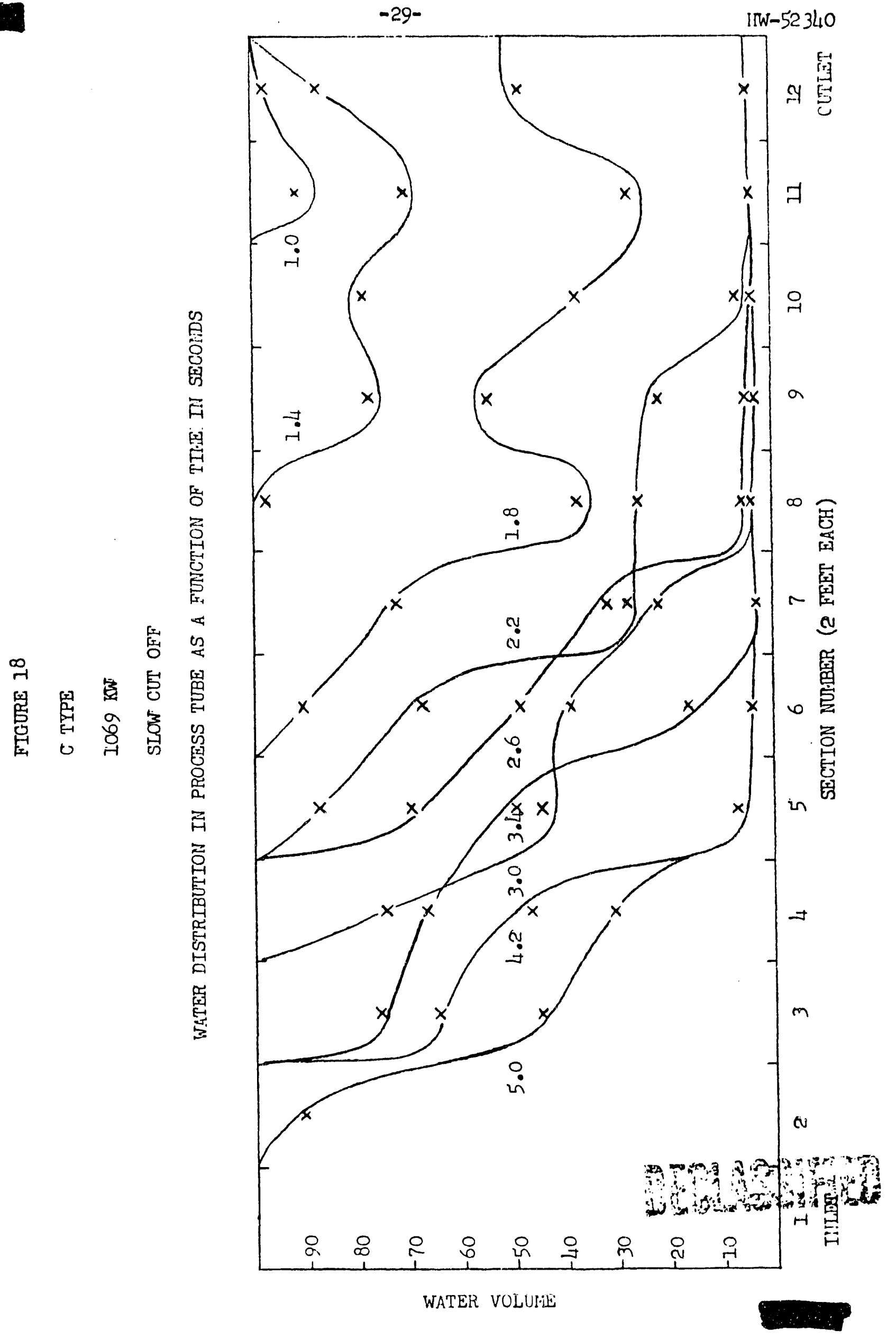




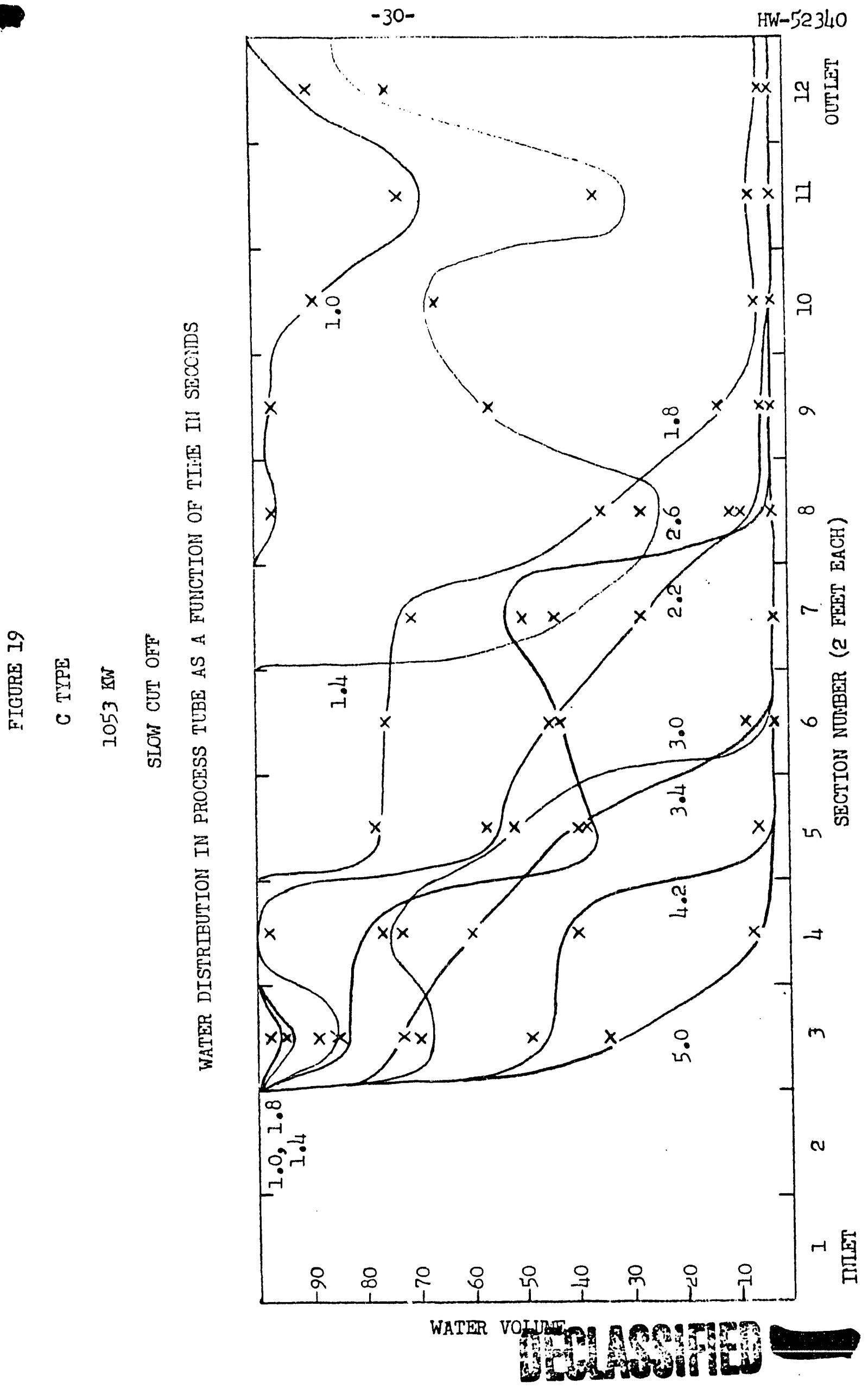




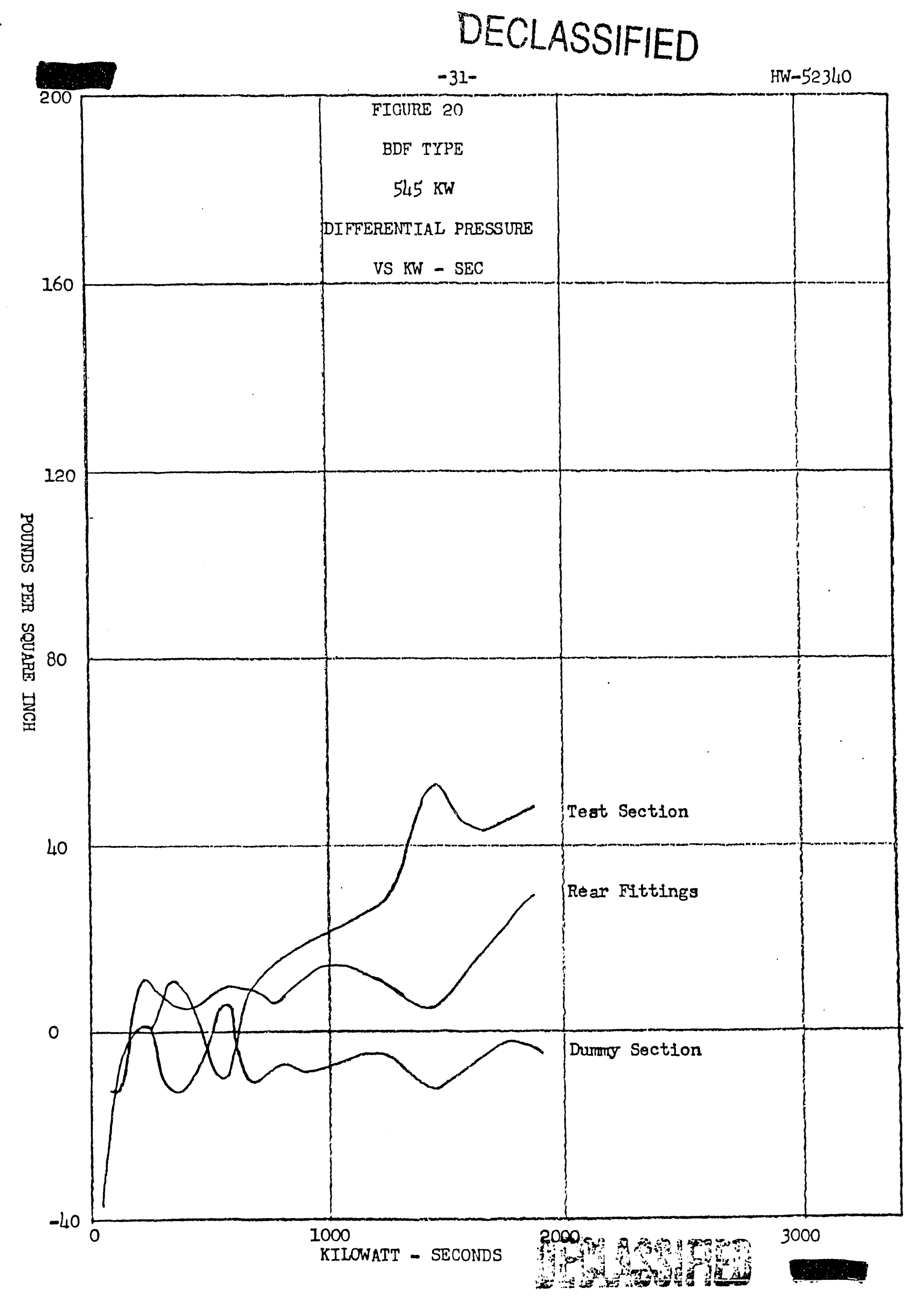




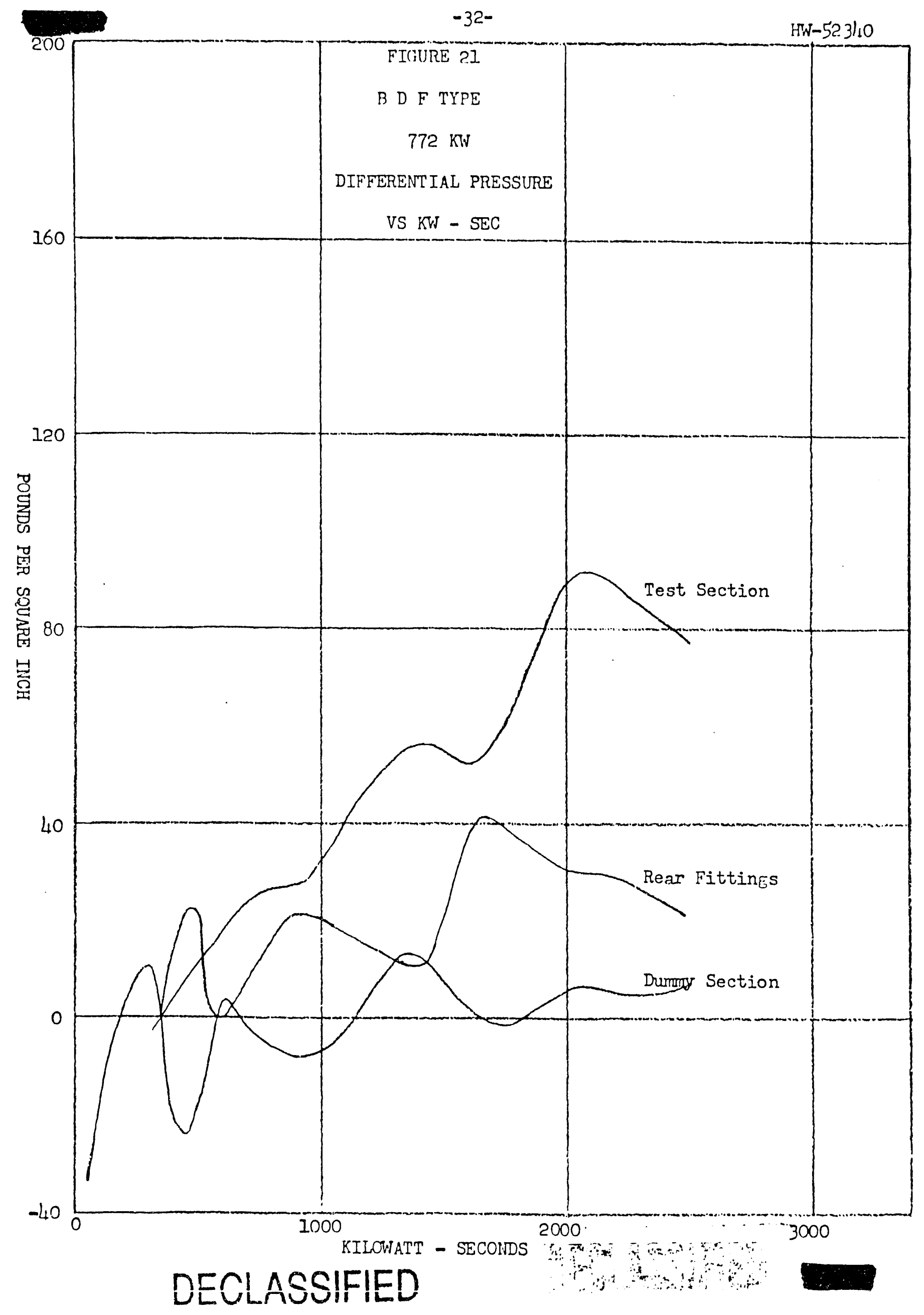




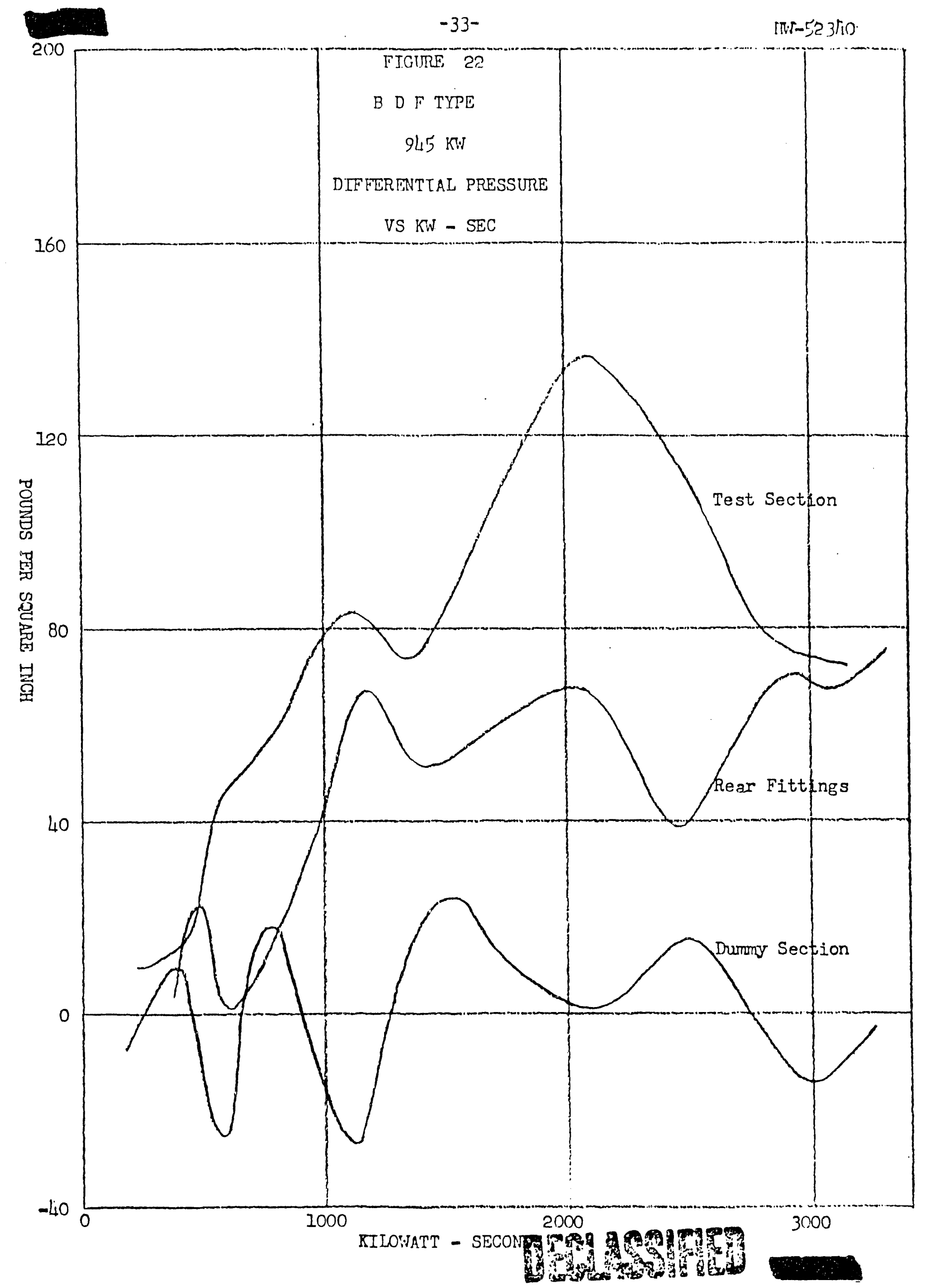




\section{DECLASSIFIED}

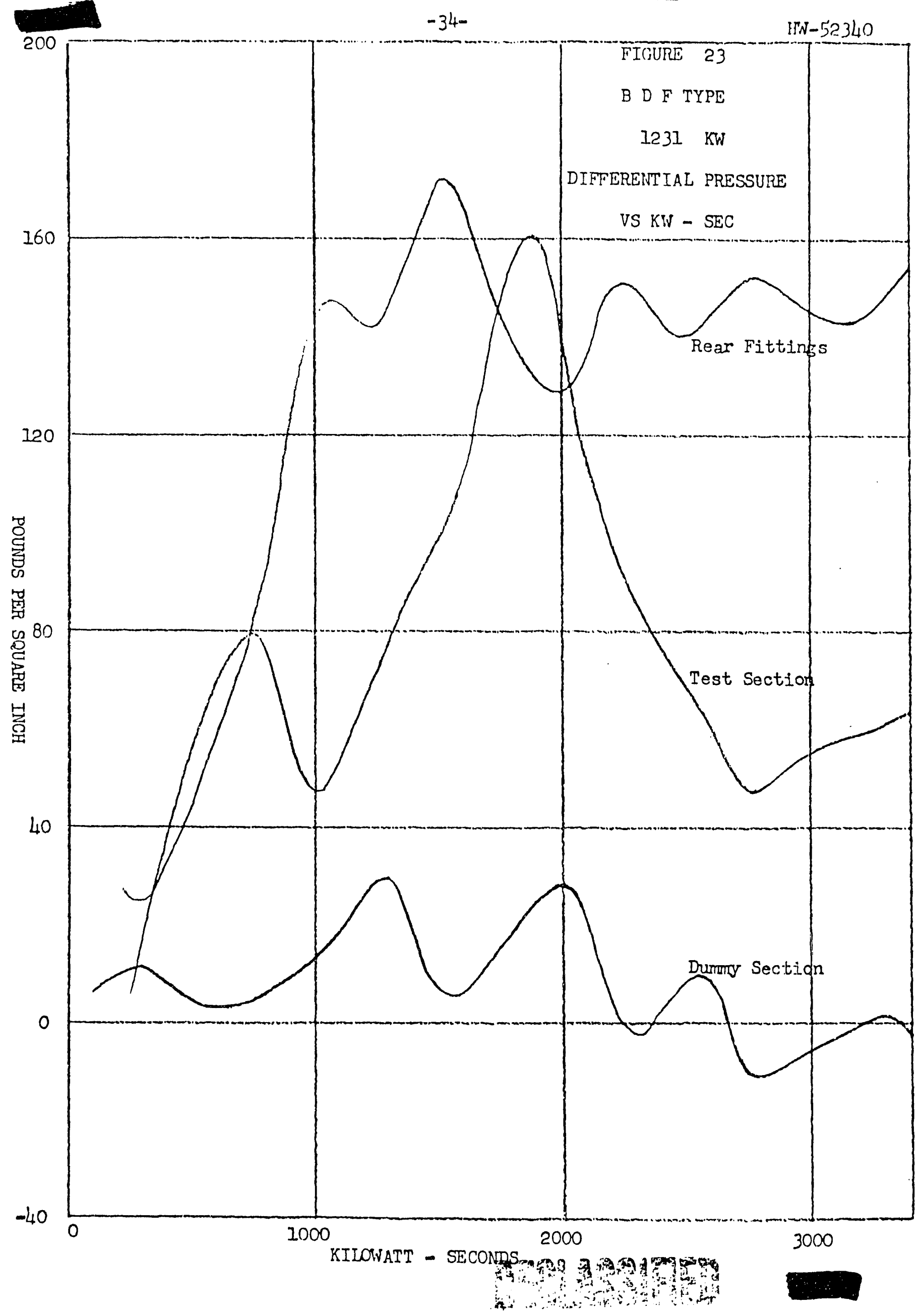




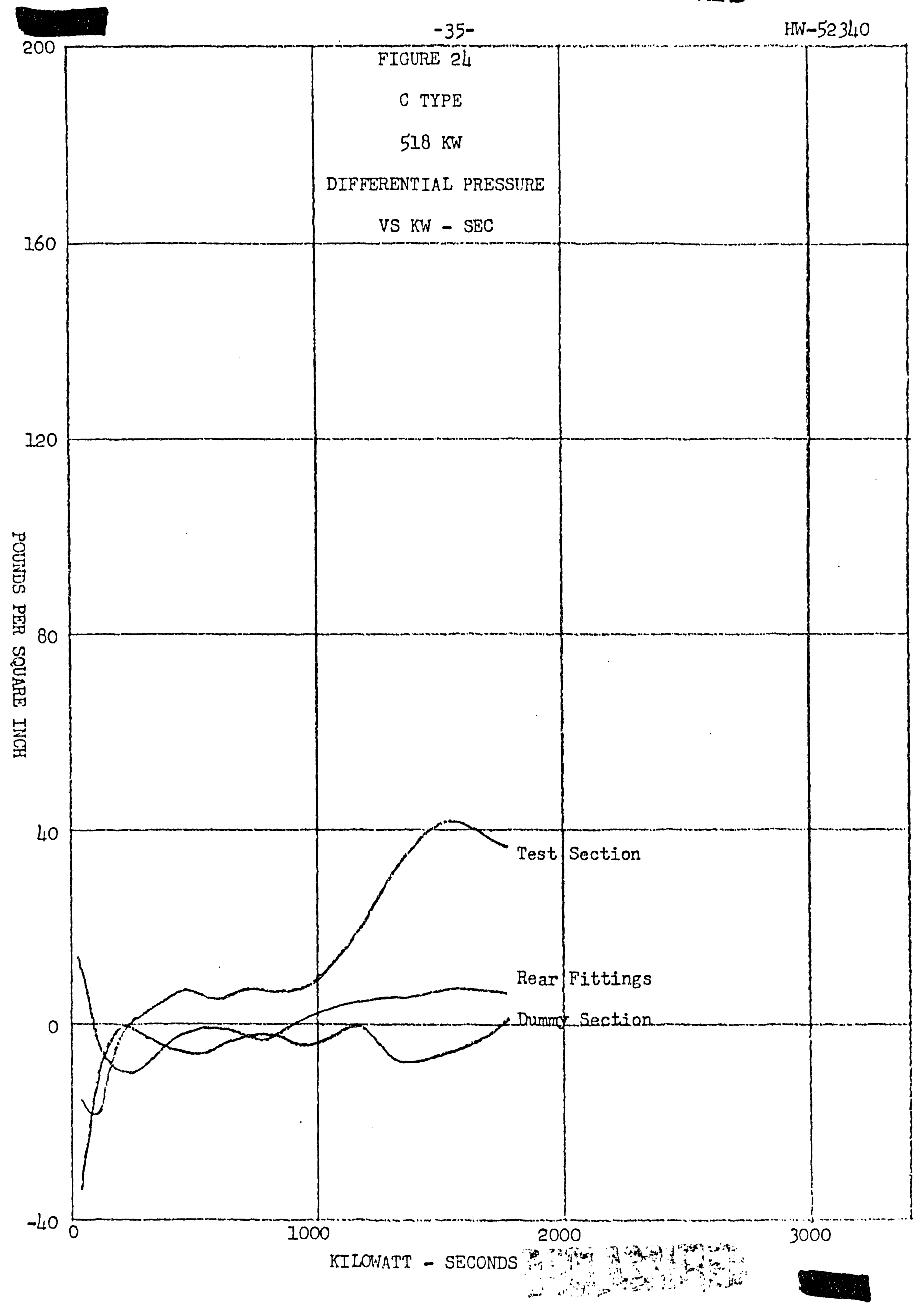




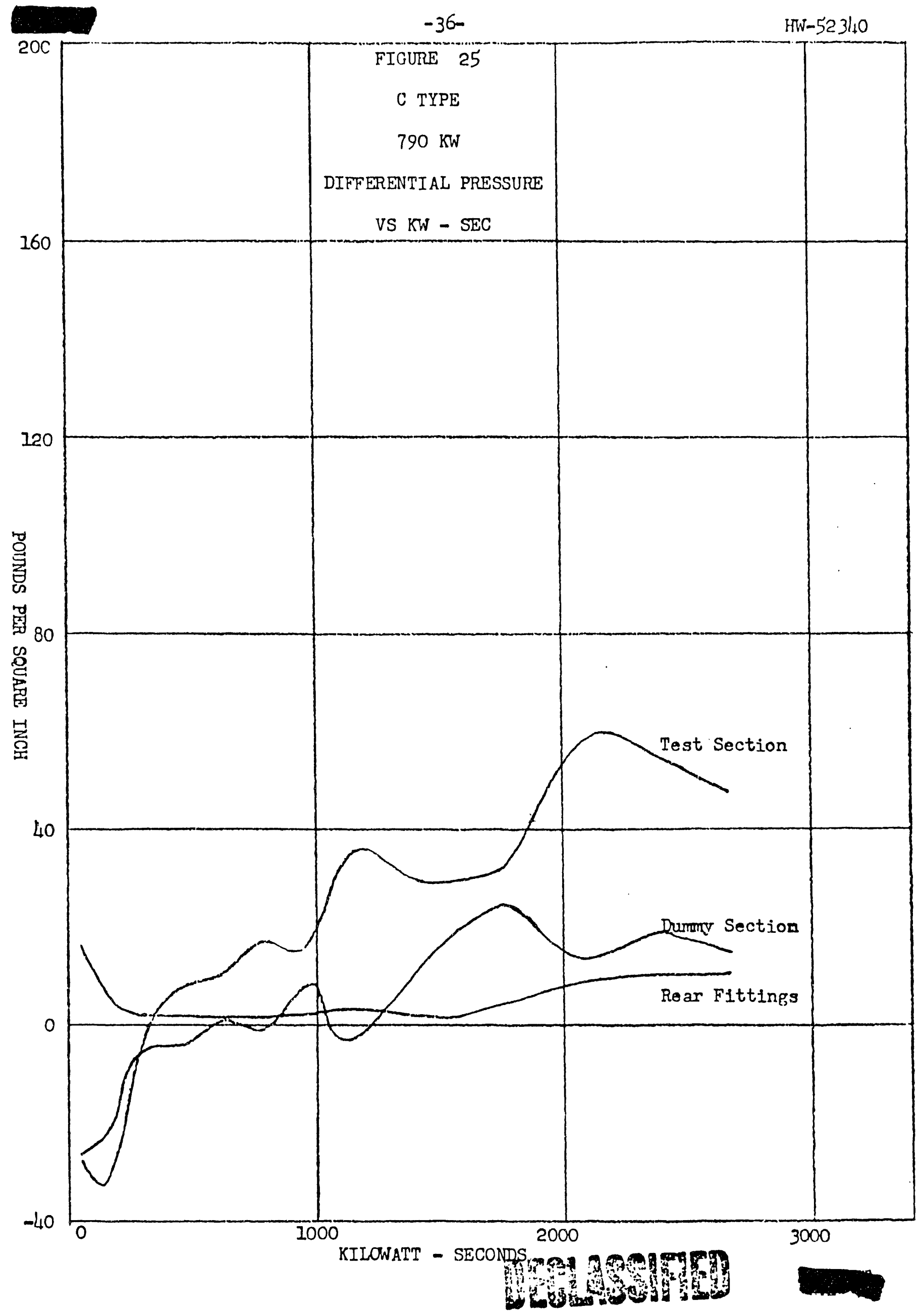




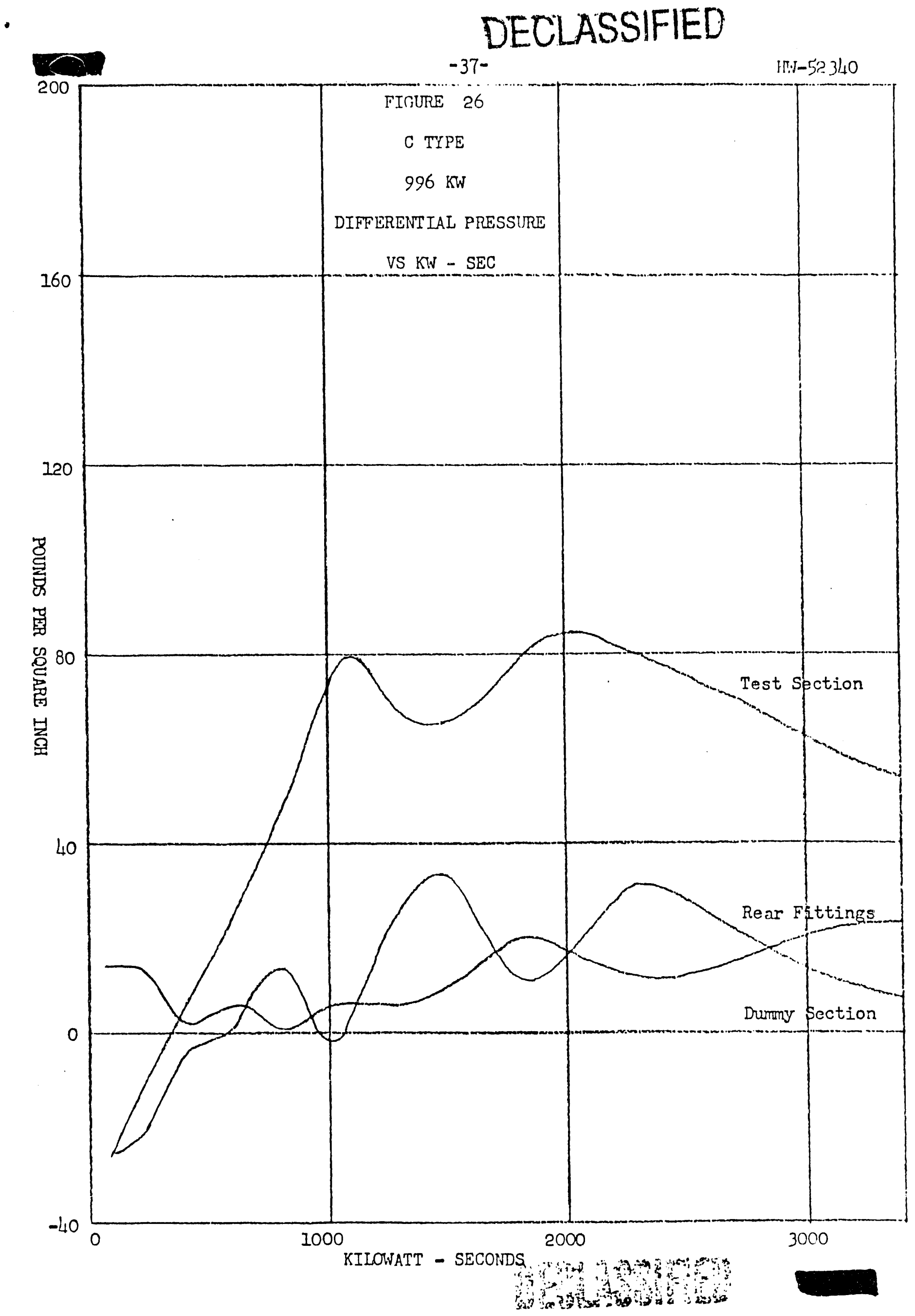




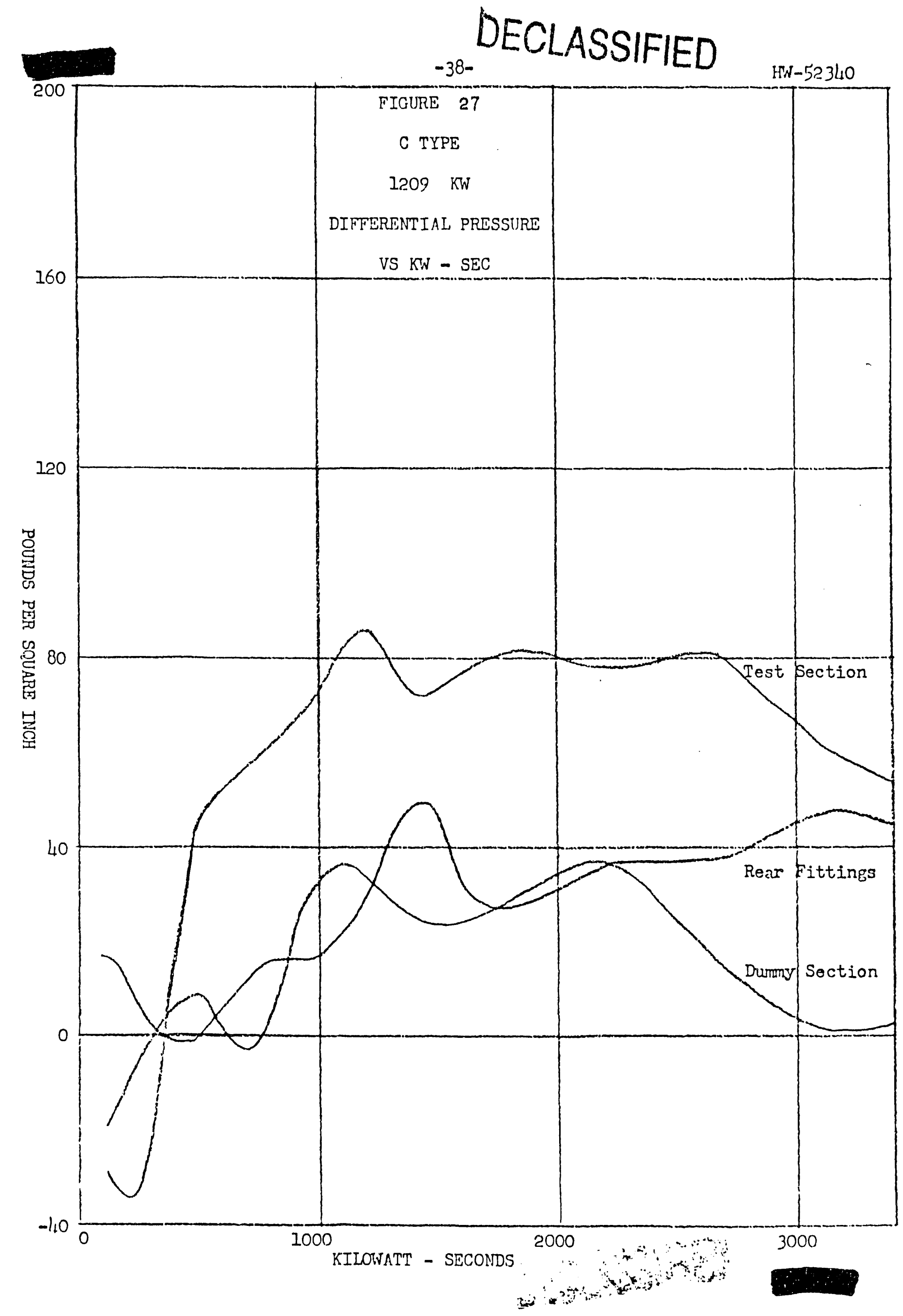




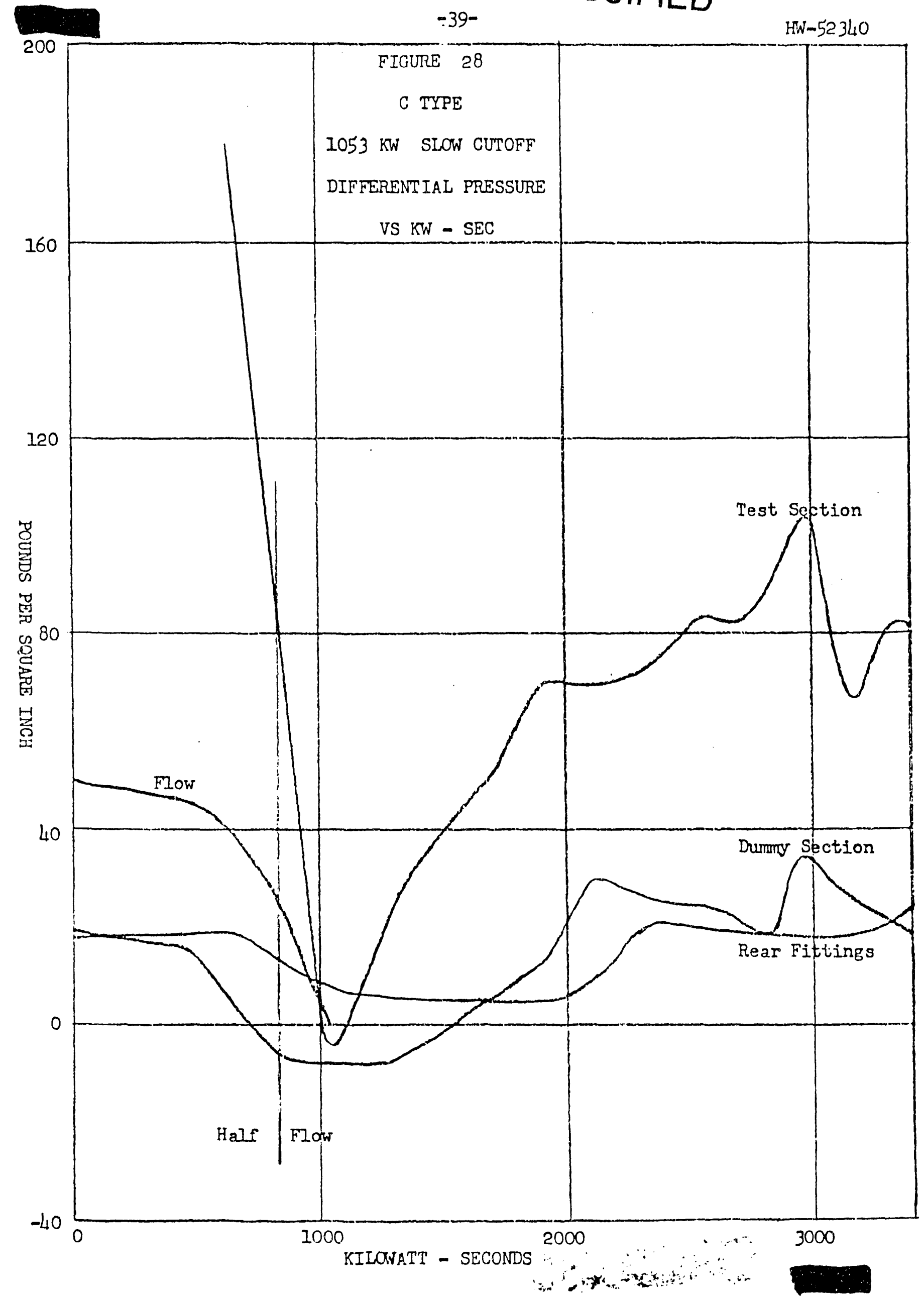




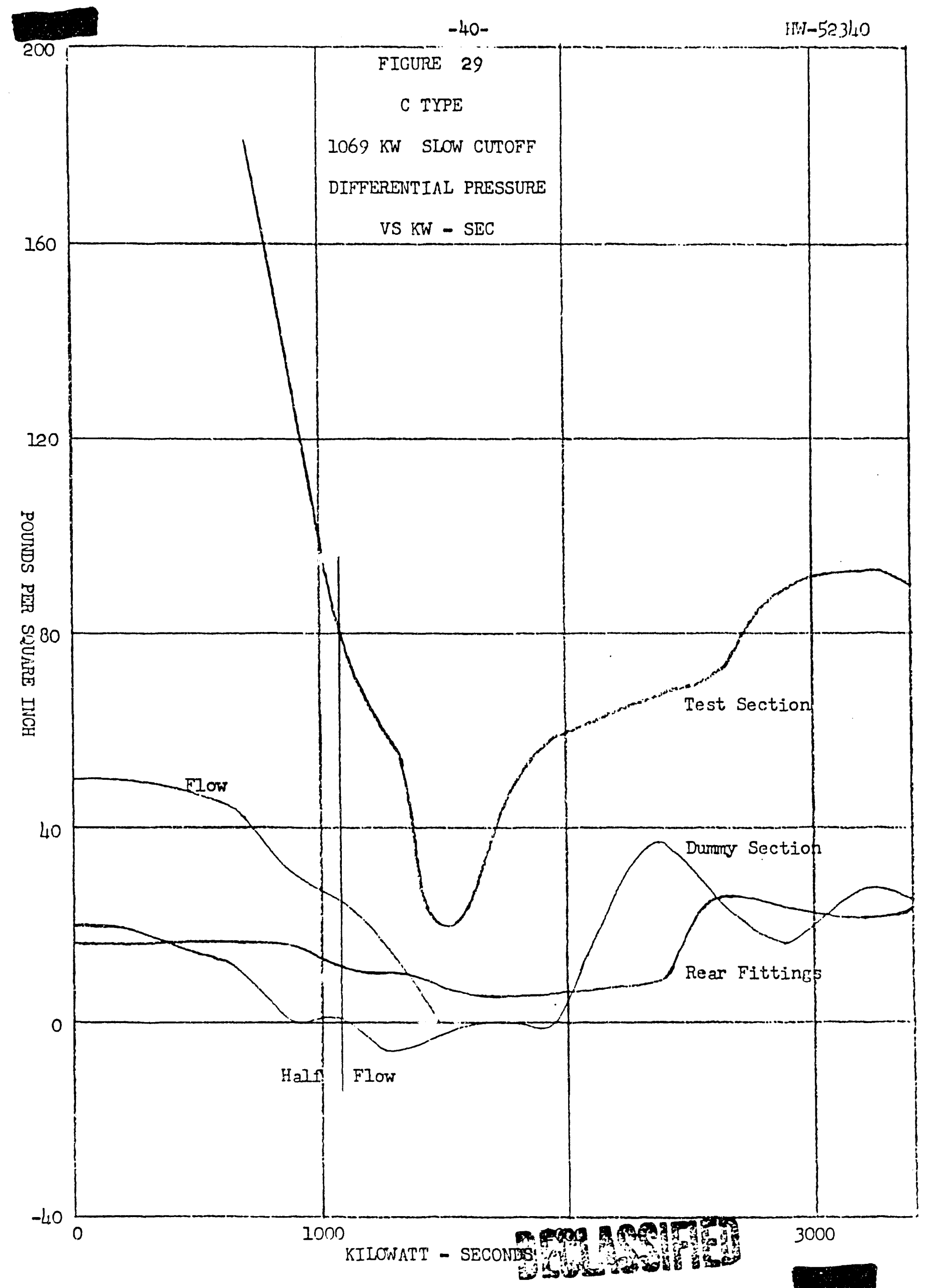




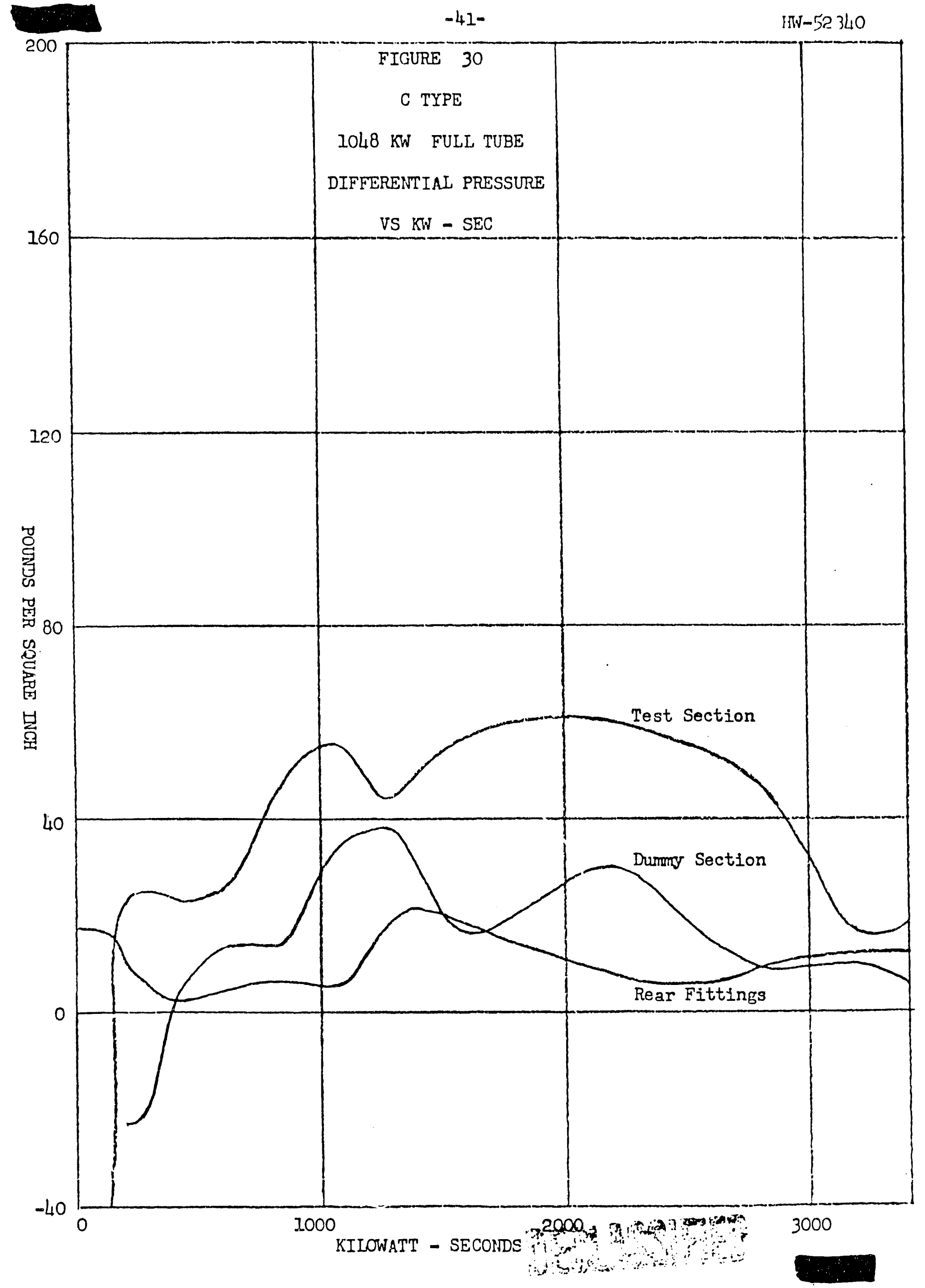




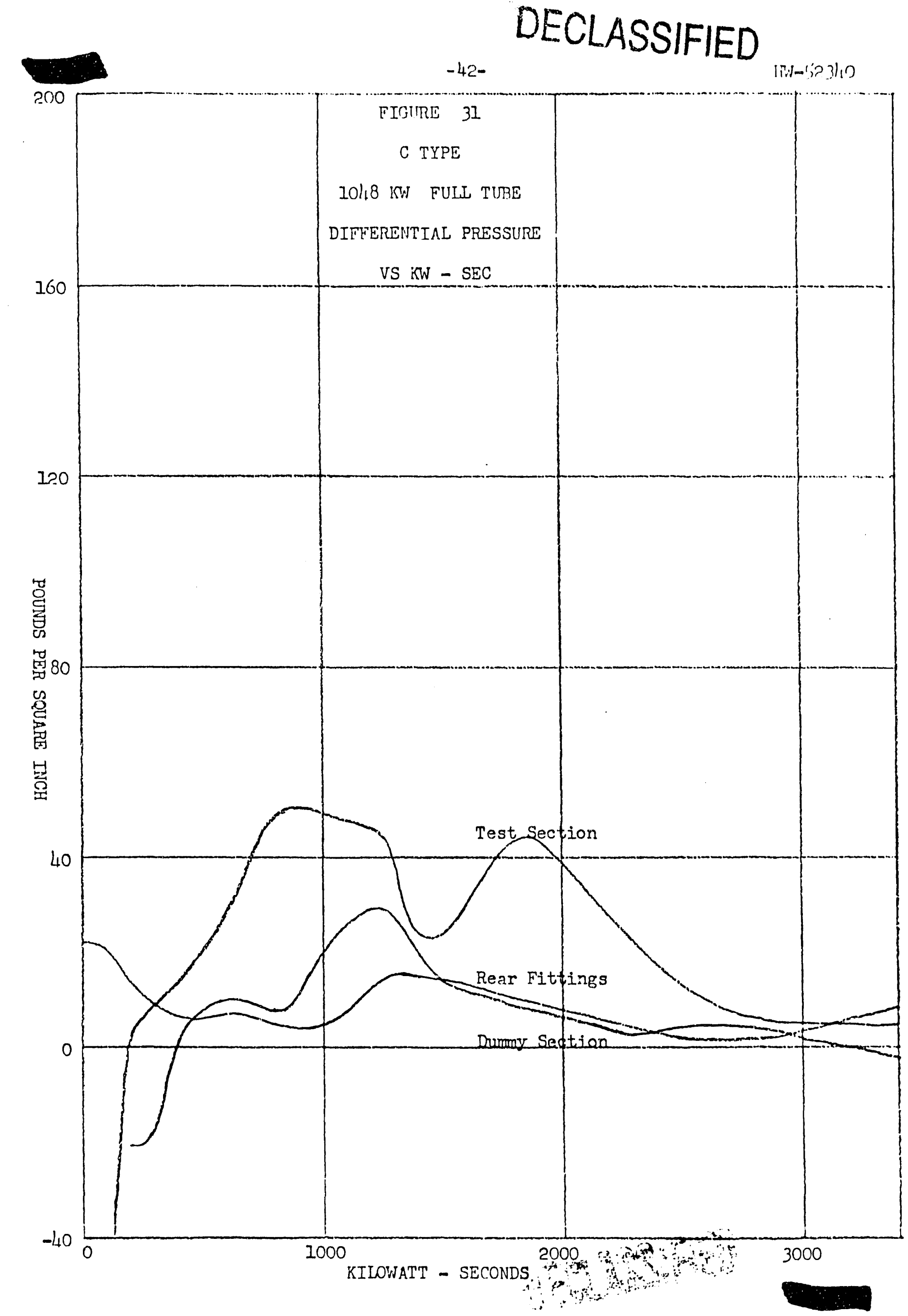



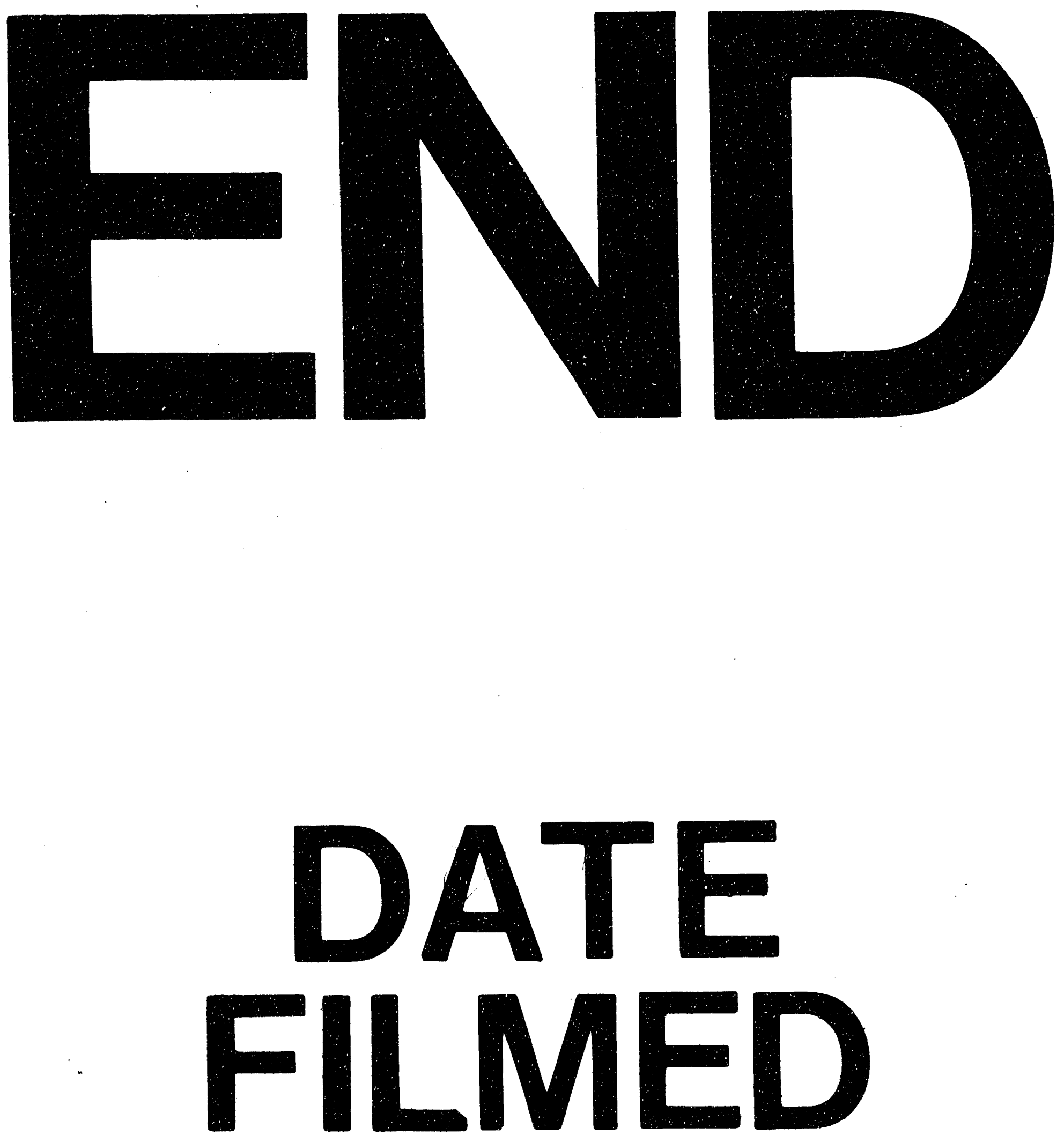

)

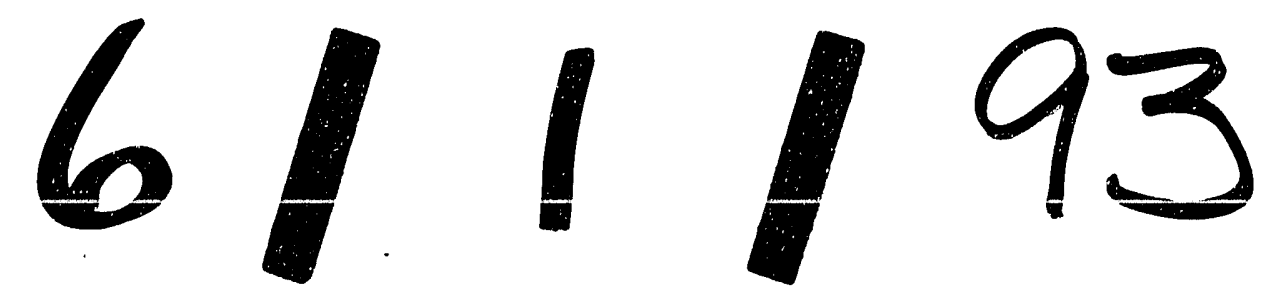


